\begin{tabular}{|l|l|}
\hline Salario mínimo y desigualdad salarial en El Salvador 2003-2014 & Titulo \\
\hline Barrera, Saira Johanna - Autor/a; & Autor(es) \\
\hline Buenos Aires & Lugar \\
\hline CLACSO & Editorial/Editor \\
\hline 2016 & Fecha \\
\hline $\begin{array}{l}\text { Mercado de trabajo; Asalariados; Desigualdad salarial; Salario mínimo; América } \\
\text { Central; El Salvador; }\end{array}$ & Colección \\
\hline Doc. de trabajo / Informes & Temas \\
\hline "http://biblioteca.clacso.edu.ar/lacso/becas/20160407022542/CLACso.pdf" & Tipo de documento \\
\hline $\begin{array}{l}\text { Reconocimiento-No Comercial CC BY-NC } \\
\text { http://creativecommons.org/licenses/by-nc-nd/2.0/deed.es }\end{array}$ & URL \\
\hline
\end{tabular}

Segui buscando en la Red de Bibliotecas Virtuales de CLACSO

http://biblioteca.clacso.edu.ar

Consejo Latinoamericano de Ciencias Sociales (CLACSO)

Conselho Latino-americano de Ciências Sociais (CLACSO)

Latin American Council of Social Sciences (CLACSO)

www.clacso.edu.ar

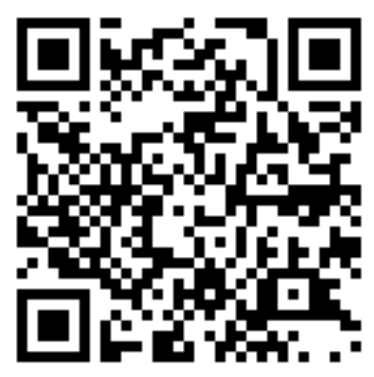




\section{Área de Promoción de la Investigación}

\section{INFORME DE INVESTIGACIÓN}


Saira Barrera*

\title{
Salario mínimo y desigualdad salarial en El Salvador
}

\author{
2003-2014**
}

\section{Resumen}

La investigación cuyos resultados se presentan en este artículo, exploró la relación entre la dinámica de los salarios mínimos urbanos y la desigualdad salarial en El Salvador en el periodo 2003-2014. La pregunta de partida es cómo ha impactado la dinámica del salario mínimo urbano a la desigualdad salarial en los últimos trece años. Las investigaciones sobre la relación entre estas variables en diferentes países de América Latina han reportado resultados heterogéneos: en Argentina, Brasil, Uruguay los incrementos en el salario mínimo han contribuido a reducir la desigualdad; en Chile esta relación es irrelevante y en México, el descenso de los salarios mínimos reales incrementa la desigualdad salarial. No se conocen estudios que exploren esta relación para el caso salvadoreño. En este trabajo estima Indice de Herfindahl y Hirschmann (IHH) para estimar la concentración en el empleo, Indice de Gini e Indice de Theil para medir el grado de desigualdad en la distribución de la masa salarial; y descomposición de las variaciones en el salario promedio sectorial para separar el efecto del empleo y los salarios por rama. Se concluye que la distribución salarial es bastante igualitaria y que los ajustes en el salario mínimo nominal urbano han contribuido con la reducción de la desigualdad salarial en el periodo 2003-2014.

\section{Palabras clave}

Salario mínimo, concentración del empleo, desigualdad salarial

*Maestra en Economía por la Universidad Nacional Autónoma de México, UNAM. Docente e investigadora del departamento de economía de la Universidad Centroamericana José Simeón Cañas, UCA.

** Reporte de investigación financiada por una beca obtenida en el Concurso La producción de desigualdades en América Latina y el Caribe, organizado por CLACSO, en el periodo octubre 2015 a marzo 2016. Agradecimientos especiales a las personas que colaboraron de diferentes formas a la realización de esta investigación: al Dr. Dídimo Castillo por sus sugerencias y observaciones; a Roberto Góchez y Lorena Valle por sus aportes en la sistematización y construcción de la base de datos; a José Llopis, Denisse Delgado y Adrián Jaén por sus recomendaciones bibliográficas. El resultado final tiene los aportes de muchas personas, pero me responsabilizo de los errores u omisiones. 


\section{Introducción}

En El Salvador, al igual que en todos los países de América Latina, el ingreso se distribuye de manera desigual. Sin embargo El Salvador es el país que tiene una menor desigualdad medida a través del índice de Gini, en relación al resto de Centroamérica. De hecho, en la última década este índice se ha reducido en El Salvador más que en los otros países centroamericanos, de tal manera que en $2014^{1}$ este índice se ubicó en 38.0; $26 \%$ menos que su valor en 2001, cuando ascendía a 51.1. Otros países de América Latina, especialmente los más grandes: México, Brasil, Argentina y Chile, también han registrado mejoras en la distribución del ingreso medida con el índice de Gini. De hecho, según datos del Banco Mundial, en Brasil y Argentina se ha registrado una reducción de $20.6 \%$ y $10.8 \%$ (respectivamente) en dicho índice en la década que va de 2001 a 2013.

La desigualdad en la distribución del ingreso no solo tiene implicaciones sociales, políticas o éticas; sino que también puede ser un importante freno para el crecimiento económico y para el desarrollo de los países (BID, 1998: 24). Por esa razón, la identificación de los elementos catalizadores o inhibidores del aumento de esta desigualdad ofrece caminos de acción para incidir sobre ella. En este esfuerzo se inscribe, por ejemplo, el Global Wages Report 2014/15, el cual encuentra que la reducción de la desigualdad queda explicada en gran medida por elementos relativos al mercado de trabajo: tanto aumentos en el salario real como la incorporación al empleo (reducción de desempleo). Para el caso brasileño, $72 \%$ de la reducción de la desigualdad top-bottom se explica por elementos del mercado de trabajo; mientras en el caso argentino el porcentaje explicado por dichos elementos es de $87 \%$. Concluye este apartado afirmando que "ningún país en la muestra [analizada] tuvo éxito en reducir la desigualdad entre el primer decil y el último [top-bottom inequality] en la pasada década sin también reducir la desigualdad en el mercado de trabajo" (ILO, 2015: 33).

Así pues, la evolución de la desigualdad salarial es uno de los elementos a considerar a la hora de explicar la reducción de la desigualdad en el ingreso. De ahí que algunos trabajos hayan centrado su atención en el estudio de los determinantes de la desigualdad salarial, entre estos se encuentran los trabajos de Carrillo y Vázquez (2005) y Arranz y García (2014).

Además, la desigualdad salarial está estrechamente ligada a la distribución del ingreso, pero no son la misma cosa (BID, 1998: 22). La dispersión en la distribución de los salarios puede ser afectada por elementos relativos a los mercados, especialmente al mercado laboral y la configuración de la demanda y la oferta laboral; elementos relacionados con -o derivados de- la política económica; o elementos ligados a las instituciones, especialmente aquéllas vinculadas al ámbito laboral (Arranz y García, 2014: 3). Esta diferencia entre desigualdad salarial y desigualdad del ingreso puede ser mayor o menor de acuerdo a las especificidades de los países, especialmente cuando hay elementos que afectan el ingreso de las personas o de los hogares que no derivan de las rentas obtenidas en el mercado laboral interno (remesas o ingresos por trabajo por cuenta propia, por ejemplo). Por ello, encontrar factores que afecten el grado o la forma de la desigualdad salarial, aporta de manera mediata en la comprensión de la desigualdad en la distribución del ingreso.

\footnotetext{
${ }^{1}$ Dato según Encuesta de Hogares de Propósitos Múltiples (EHPM) de 2014.
} 
Por su parte, la desigualdad salarial puede tener entre sus elementos explicativos algunas instituciones laborales, entre las cuales puede señalarse al salario mínimo y, aunque el salario mínimo no es la única (y quizá tampoco la más importante institución laboral en algunos países para los existen estudios en esta línea ${ }^{2}$ ), en el país de interés de esta investigación (El Salvador), el salario mínimo constituye la institución laboral de mayor incidencia. Las otras instituciones que han jugado un papel relevante en otros países (seguros por desempleo y establecimiento de contratos colectivos de trabajo) son, en este caso en particular, inexistentes (como el seguro por desempleo) o muy poco extendidas (como el contrato colectivo de trabajo).

En este sentido, puede ser esperable que la dinámica que sigan los salarios mínimos sea el componente institucional que tiene más impacto en la dispersión salarial, en tanto puede comprimir las remuneraciones alrededor de ciertos valores y alejar o acercar a las personas de los estratos más bajos respecto a los estratos medios y superiores de la distribución salarial. Así pues, con esta inquietud en mente se planteó la presente investigación a partir de la siguiente pregunta: ¿Cuál es el impacto que ha tenido el salario mínimo urbano y sus variaciones, en la desigualdad salarial en El Salvador en los últimos trece años?

El objetivo que se persigue es contribuir a la comprensión del impacto y la importancia que tienen los salarios mínimos en la desigualdad salarial en El Salvador. La hipótesis de partida fue que dinámica de los salarios mínimos urbanos hizo crecer la desigualdad salarial en El Salvador en el período 2000-2014. Esta hipótesis fue concebida a partir de la noción de que la masa salarial se distribuía de manera desigual y que los estrechos ajustes en el salario mínimo en la zona urbana ampliaban la distancia de estos respecto a los mayores salarios. Como se verá posteriormente, los resultados invalidaron esta hipótesis.

Para lograr el objetivo propuesto, se siguió la siguiente estructura de exposición: en un primer apartado desarrolla la fundamentación teórica relativa a la desigualdad salarial, los salarios mínimos y la relación entre estas dos variables. En seguida, un segundo apartado expone la metodología seguida para abordar la temática planteada. En tercer lugar, se presenta el apartado en el que se exponen los hallazgos encontrados, comenzando por los relativos a la ubicación de los empleos entre los sectores y la concentración de estos entre las ramas productivas de cada sector; luego se presentan los hallazgos relativos al salario mínimo, el salario promedio y la relación entre ambos $\mathrm{y}$, finalmente se presentan los índices de desigualdad salarial y los elementos que apuntan al salario mínimo como elemento clave para comprender la evolución de esta desigualdad. En un último apartado se presentan las conclusiones a las que se llegó y la bibliografía consultada.

\footnotetext{
${ }^{2}$ Véase por ejemplo, para el caso de España y otros países de la OCDE el trabajo de Arranz y García (2014). También puede consultarse, para el caso de Chile, el trabajo de Maurizio (2014).
} 


\section{Teoría sobre la desigualdad salarial y el salario mínimo}

La mayoría de estudios sobre desigualdad salarial adoptan como marco teórico la teoría del capital humano, ya sea de manera parcial o de manera completa. Según esta teoría, las inversiones en capital humano (educación, especialización, etcétera) aportan retornos económicos a las personas y empresas que la realizan debido a que los años adicionales de educación reportan un mayor salario para quien trabaja; y este a su vez es fruto de una mayor productividad. De esta manera los años de estudio, al constituir una base de diferenciación del factor trabajo -que en la versión más ortodoxa del planteamiento neoclásico es un bien homogéneo- también constituirían la base de una estructura diferenciada de remuneraciones.

El estudio de Carrillo y Vázquez (2005) es un ejemplo del uso de este marco teórico para explicar la desigualdad salarial en México. Según estos autores, las diferencias en el nivel educativo de las personas trabajadoras en México son, efectivamente, uno de los principales elementos explicativos de la desigualdad salarial en ese país. Arranz y García (2014) también adoptan este marco, aunque de manera parcial, cuando afirman que una de las razones por las cuales se ha reducido la desigualdad salarial en España es que se han reducido los retornos por años adicionales de educación.

La desigualdad salarial también ha sido estudiada considerando el papel de la organización al interior de las empresas y de las instituciones que rigen el mercado de trabajo, pero sin renunciar a los postulados básicos relativos al funcionamiento del mercado de trabajo en el paradigma neoclásico, es decir, sin abandonar la idea de que existe una oferta y una demanda de trabajo resultantes de procesos de optimización de los trabajadores y de los empresarios, respectivamente. En un contexto de competencia perfecta, esta oferta y demanda de trabajo interactúan, convergen y determinan simultáneamente el salario de equilibrio y el nivel de empleo que es, a su vez, pleno empleo.

Las instituciones que rigen el mercado de trabajo y afectan los ajustes ya sea por el lado de la oferta o de la demanda son: los seguros por desempleo, el establecimiento de contratos colectivos de trabajo, lo cual implica la existencia y actividad de sindicatos; y el salario mínimo. Cabe aclarar que la influencia de estas instituciones sobre el mercado de trabajo de un país determinado depende de cuáles de estas instituciones existen en dicho país, de cuál es su alcance y de las particularidades del mercado laboral en cuestión. Arranz y García (2014), por ejemplo, indican que en los países de la OCDE se han realizado diversos estudios para encontrar los elementos explicativos de la desigualdad salarial en varios países y, entre los elementos que aparecen reiteradamente se encuentran las características de las empresas (establecimientos) y la firma de contratos colectivos ${ }^{3}$.

Por su parte, Maurizio (2014) señala que las mejoras en los salarios mínimos reales y la mayor formalización de trabajadores en Brasil, Argentina y Uruguay explican la reducción en la desigualdad salarial en esos países, mientras que otro país incluido en este estudio, Chile, evidencia que el salario mínimo no ha jugado un papel relevante en la desigualdad salarial, lo cual puede deberse a la menor formalización de trabajadores en comparación con los otros países, o al ínfimo crecimiento del salario mínimo en ese país, especialmente en relación con los otros tres.

\footnotetext{
${ }^{3}$ Puede encontrarse una tabla que detalla a los autores de estos trabajos y los principales hallazgos en lo relativo a los determinantes de la dispersión salarial en uno o varios países de la OCDE en Arranz y García (2014: 16).
} 
Fairris, Popli y Zepeda (2005) sostienen que la desmejora en el salario mínimo real en México no solo no es irrelevante en la desigualdad salarial, como habrían apuntado otros estudios relativos al tema, sino que es un elemento que explica la persistencia y ampliación de esta desigualdad en México y esto es especialmente cierto después de la aplicación de los planes de ajuste estructural. En otro estudio, Gindling y Terrell (2007 y 2011) afirman que los aumentos en el salario mínimo real tienen un efecto positivo sobre los salarios de los trabajadores que permanecen en el sector cubierto después del incremento, sin embargo, este efecto positivo del incremento en los salarios mínimos suele circunscribirse a aquéllos trabajadores que ganan salarios alrededor del valor de éstos mínimos, no así aquéllos que están más alejados de estos valores, especialmente los de mayor salario. Visto desde esta perspectiva, se deduce que una mejora en los salarios mínimos podría reducir la desigualdad salarial en tanto mejora en mayor medida los ingresos de los estratos más bajos de asalariados en relación a los de mayor salario.

Estos hallazgos sobre la incidencia del salario mínimo en la desigualdad salarial se inscriben en una concepción teórica más amplia sobre la existencia y los impactos del salario mínimo sobre el funcionamiento del mercado de trabajo, la cual se ha circunscrito al paradigma neoclásico, que a su vez está sustentado en los planteamientos marginalistas o en elaboraciones de los mismos. Por ejemplo, el planteamiento de que los salarios mínimos constituyen una rigidez de mercado que puede generar desempleo involuntario cuando su monto se ubica por encima del salario de equilibrio, se basa en la premisa teórica de que el salario real es igual a la desutilidad marginal de determinado volumen de ocupación, por el lado de la oferta; y a la productividad marginal de trabajo, por el lado de la demanda (FUSADES, 2010: 3; Gindling y Teller, 2011; Gindling y Teller, 2007).

Esta premisa teórica fue cuestionada por Keynes (2003: 38-53) en la primera mitad del siglo XX, pero aún inspira la mayoría de estudios realizados en países de diversos grados de desarrollo:

"Los investigadores del Salario Mínimo tienen especializaciones en los países que, en general, tienen mayores niveles de productividad científica, coincidiendo así con la tendencia mundial del tema. Adicionalmente, es importante remarcar que la concentración en estos países tiene importante implicancias epistemológicas y políticas, ya que es evidente que -aún cuando muy heterogéneo- el proceso de producción de conocimiento en políticas públicas en estos países tiene como principal enclave las teorías económicas clásicas, constituyendo así una "matriz fundacional" para el análisis de los efectos del salario mínimo.” (Pérez y Villalobos, 2014: 6; énfasis propio).

Otro planteamiento teórico relacionado con el anterior es el denominado modelo bisectorial según el cual, un incremento en el salario mínimo reduce el empleo en el sector cubierto y lo acrecienta en sector no cubierto (Gindling, 2007: 2-3). Las investigaciones de Gindling y Terrell (2007 y 2011) para los países centroamericanos son ejemplo de trabajos que adoptan estas premisas y las someten a validación estadística. Los hallazgos de estas investigaciones indican que en Costa Rica y Nicaragua; los incrementos en el salario mínimo tienen un efecto negativo sobre el empleo y sobre las horas promedio trabajadas en el sector cubierto ${ }^{4}$. Y en el caso de El

\footnotetext{
4 Se refieren a la porción de trabajadores para los cuales es aplicable la tarifa de salario mínimo, es decir, aquéllos registrados como asalariados. Por su parte, el sector no cubierto incluiría a personas que trabajan por cuenta propia (con local o sin local), familiares no remunerados
} 
Salvador, el estudio de FUSADES (2010) señala que los incrementos en los salarios mínimos pueden tener impactos negativos en la permanencia en el empleo formal de los trabajadores y aumenta las probabilidades de pasar a ser asalariado temporal o de pasar de la formalidad a la informalidad.

En relación al impacto que tienen los ajustes en el salario mínimo sobre el resto de remuneraciones, se plantea que los salarios mínimos pueden funcionar como una especie de faro (lighthouse effect) para el establecimiento de las remuneraciones en el sector no cubierto (Gindling, 2007: 13); de tal manera que el alza en los salarios mínimos arrastraría al resto de remuneraciones al alza, impactando de forma positiva en los ingresos de una mayor parte de trabajadores y trabajadoras y amplificando, por esta vía, su incidencia en la distribución de los salarios e ingresos ${ }^{5}$. A esto último es a lo que Maurizio (2014: 8) denomina efecto censura.

En esta línea, la investigación de Gindling y Terrell para Costa Rica (2007) y Nicaragua (2011) aseguran que no se cuenta con evidencia empírica de que el efecto faro ocurra en alguno de esos tres países. Más bien, la evidencia empírica para estos países sugiere que los salarios mínimos no tienen un impacto ni positivo (lighthouse effect) ni negativo como podría deducirse de la visión teórica del mercado de trabajo bisectorial (cubierto-no cubierto).

Sin embargo, para saber el impacto final de los aumentos en el salario mínimo sobre la desigualdad salarial, es necesario considerar, además del efecto censura, lo que Maurizio (2014) denomina efecto truncamiento, el cual se refiere a que puede existir una pérdida importante de empleos de bajo salario fruto del aumento en el salario mínimo, lo cual puede implicar mejoras en el salario promedio dada la menor incidencia de los menores salarios ponderado por el número de personas que lo ganan.

Por tanto, el salario mínimo influye en la distribución salarial y también en la distribución del ingreso; y esta influencia dependerá de si el efecto truncamiento es mayor o menor que el efecto censura. Por ejemplo, en el primero de los casos, el resultado final del incremento en el salario mínimo será perjudicial para la distribución, en tanto la mejora en los salarios de los trabajadores que percibieron el incremento, se verá acompañada por una cantidad de personas que perdieron su empleo o cuyas condiciones de trabajo fueron precarizadas a raíz del incremento, con lo cual su posición en la distribución salarial y de los ingresos empeorará y, a nivel agregado, ello no será compensado con la mejora de las personas que preservaron su empleo y mejoraron su salario. Por otra parte, si el efecto censura supera al efecto truncamiento, es decir, si la mejora en los salarios mínimos no se acompaña de pérdida de empleo e incluso ocurre un incremento en la cantidad de empleos, el efecto sobre la distribución salarial y del ingreso es positivo, ya que reduce la desigualdad.

Los estudios revisados hasta este momento, se basan en las concepciones teóricas señaladas previamente y centran sus esfuerzos en validar (o no) estadísticamente alguno de los diferentes planteamientos relativos al salario mínimo y su impacto en un mercado de trabajo y en la distribución salarial (y del ingreso) de un país específico en determinado momento del tiempo. En este sentido, la presente investigación se inscribe

\footnotetext{
${ }^{5}$ En esta investigación se parte de la premisa de que ingreso y salario son dos variables diferentes. El ingreso de los hogares cuenta entre sus fuentes a los salarios, pero también a las transferencias (públicas y privadas), a las remesas y a los ingresos derivados del autoempleo. Los salarios, por su parte constituyen remuneraciones que presuponen la existencia de una relación de dependencia entre patrono y trabajador/a asalariado/a.
} 
en la constatación de la relevancia o no de las variaciones salario mínimo como elemento que impacta la desigualdad salarial.

También debe señalarse que la variable desigualdad salarial se entenderá como equivalente a la de dispersión salarial. Esta dispersión salarial se refiere a la manera como se distribuyen la masa salarial, es decir, el monto total de dinero destinado a pagar salarios por parte de las empresas; entre las personas asalariadas. Como se mencionó previamente, desde la visión convencional del capital humano esta distribución se hace atendiendo a diferentes características individuales, especialmente las relativas a la educación. Otros abordajes incorporan al análisis la organización de las empresas y las instituciones que rigen el mercado de trabajo (Arranz y García, 2014; Becker, 1983: 42). Así, esta dispersión salarial puede reducirse, por ejemplo, cuando ocurren cambios institucionales que reducen la distancia entre las personas asalariadas de menores ingresos y las de capas superiores (salario mínimo o contratos colectivos, por ejemplo); o cuando se reducen los retornos económicos por años adicionales de estudio, por ejemplo.

Ahora bien, las diferencias salariales vistas de esta última perspectiva considerar que los determinantes de los salarios son, en mayor medida, individuales. Sin embargo, una mirada desde la agregación por ramas productivas, muestra que la remuneración promedio de una persona trabajadora en una rama en relación a otra persona que labora en otra rama admite un abordaje diferente, ya que hay elementos de la estructura productiva y elementos institucionales que afectan la distribución de la masa salarial entre personas de diferentes ramas. Entre estos elementos institucionales está el salario mínimo, especialmente cuando éste se establece atendiendo a la actividad productiva en la que se genera el empleo: una mayor tarifa de salario mínimo para una rama productiva en relación a la tarifa aplicable a otra rama, puede afectar la distribución de la masa salarial entre ramas, tanto por sus efectos directos sobre el salario nominal de las personas empleadas, como por los cambios en la composición del empleo y la sucesiva incorporación (o salida) de personas que devengan estas remuneraciones. Ello actuando en concomitancia con los cambios de organización al interior de las empresas, el quehacer sindical y los incrementos en los años de estudio de las personas trabajadoras.

Por tanto, identificar los efectos del salario mínimo sobre los movimientos en el empleo, las remuneraciones promedio y la desigualdad salarial, requiere del cruce de variables de análisis referidas a características individuales, a características de las empresas, a características de las ramas productivas y a instituciones laborales.

En esta investigación se adopta una mirada a nivel de las ramas productivas y considerando una de las instituciones laborales, que es el salario mínimo. Se indicarán los hechos que vinculan al salario mínimo con la desigualdad salarial al nivel de ramas productivas, dejando para estudios posteriores la incorporación de otras variables que enriquecerán la comprensión sobre la relación entre salarios mínimos y desigualdad salarial a niveles de empresa y de individuo.

\section{Metodología}

En esta investigación se utilizó una metodología cuantitativa que supuso, en primera instancia, la construcción de una base de datos de empleo ${ }^{6}$ y salarios. Esto se logró

\footnotetext{
${ }^{6}$ Se entenderá por empleo aquélla situación en la que una persona se obliga con respecto a otra bajo una relación de
} 
sistematizando los registros de la cantidad de personas cotizantes y el monto de salarios mensuales pagados en cada rama productiva, según el Instituto Salvadoreño del Seguro Social (ISSS) en el período 2003-2014, con un nivel de desagregación de 4 dígitos de la Clasificación Industrial Internacional Uniforme (CIIU) revisión 2 para el período 20032007 y CIIU revisión 3 para el periodo 2008-2014. También fue necesario un proceso de compatibilización de códigos según lo propuesto por la Organización de las Naciones Unidas, para construir una serie completa y homogénea para todo el periodo de interés de la investigación.

Se utilizan las tarifas oficiales de salario mínimo urbano aprobadas por la Asamblea Legislativa de El Salvador y registradas en el Diario Oficial. Estas tarifas corresponden a las actividades de Comercio y Servicios, Industria Manufacturera excluyendo maquila; y Maquila textil y de la confección ${ }^{7}$.

La unidad de referencia para el análisis fue la persona trabajadora cotizante al ISSS que gana el salario nominal promedio en cada una de las ramas económicas del sector secundario y terciario ${ }^{8}$, con un nivel de desagregación de dos dígitos de la CIIU revisión $2^{9}$. Este salario se mide en dólares mensuales por persona.

El procesamiento de los datos se realizó de la siguiente manera: uso de estadística descriptiva para cuantificar el empleo en los sectores secundario y terciario de El Salvador, con la finalidad de delimitar el universo de estudio de esta investigación y el alcances de las conclusiones que de ella puedan derivar. También se calculó el índice de concentración de Herfindahl \& Hischmann $(\mathrm{IHH})^{10}$. Este índice suele utilizarse para medir concentración de las ventas entre las empresas de una industria. En este estudio se utilizó la proporción del empleo de cada rama productiva en relación al empleo de cada sector en lugar de la proporción de ventas. Se calculó así:

$I H H_{s}=\sum_{i=1}^{12} \varphi_{i}^{2}$; Este es el cálculo para el sector secundario, que cuenta con doce ramas productivas; $\varphi_{i}$ es la proporción que representa el empleo en la rama "i" respecto a todo el sector secundario.

$I H H_{T}=\sum_{i=1}^{14} \varphi_{i}^{2}$; Este es el cálculo para el sector terciario, que cuenta con catorce ramas productivas; $\varphi_{i}$ es la proporción que representa el empleo en la rama "i”" respecto a todo el sector terciario.

Los valores de este índice oscilan entre 0 y 10,000 y su interpretación, adaptada a las finalidades de este estudio, es así:

IHH<1500: Empleo no concentrado. $1500<\mathrm{IHH}<2500$ : Empleo moderadamente concentrado.

\footnotetext{
dependencia laboral que permite a la primera cotizar al ISSS.

${ }^{7}$ Las otras seis categorías de salario mínimo están ligadas a labores que se realizan mayoritariamente en el área rural: agricultura, corta de algodón, de caña de azúcar y de café; y trabajadores de los beneficios de café y algodón.

${ }^{8}$ Véase el anexo 4 para verificar cuáles ramas productivas se han considerado en cada sector.

${ }^{9}$ Esto implica que han quedado fuera las características individuales que pudieran incidir en el salario individual percibido por cada persona cotizante al ISSS: nivel educativo, edad, sexo. No se dispone de esa información de las personas cotizantes.

${ }^{10}$ Se utilizó el cálculo propuesto por Bolaños, Góchez y Salgado (2010: 61).
} 
2500<IHH: Empleo altamente concentrado.

Este cálculo se realizó con la finalidad de visibilizar la distribución de empleo, la cual tiene implicaciones en la desigualdad salarial dado que la tarifa mínima no es la misma para todas las ramas productivas.

Por otra parte, la desigualdad en una distribución suele cotejarse con un parámetro considerado equitativo o deseable, el más usado es la regla democrática que constituye la base teórica del indicador de distribución del ingreso más usado, que es el Índice de Gini (Cortés y Rubalcava 1984: 12). Por tanto, para estimar el grado de desigualdad en la distribución de la masa salarial se calculó el Índice de Gini correspondiente a esa distribución en cada año desde 2003 hasta 2014, siguiendo la expresión:

$$
I G_{t}=\frac{\sum_{i=1}^{25} p_{i t}-q_{i t}}{\sum_{i=1}^{25} p_{i t}}
$$

Donde $p_{i t}$ es la participación acumulada de la rama "i” en el empleo total; y por otra parte, $q_{i t}$ es la participación acumulada de la masa salarial de la rama "i”" en la masa salarial total. El subíndice "i" tiene como valor superior 25 porque se cuenta con datos para 26 ramas productivas y la sumatoria se realiza respecto a (n-1) datos. Este índice puede tomar valores de 0 a 1 , donde 0 es completa igualdad y 1 es extrema desigualdad.

También se calculó Indice de Theil como medida adicional de concentración. Este tiene ventajas respecto al uso del índice de Gini $^{11}$ y arroja información sobre los cambios en la distribución. Se calcula así:

$H_{t}=\sum_{i=1}^{26} q_{i t} \ln \left(\frac{q_{i t}}{p_{i t}}\right)$; Donde $q_{i t}$ representa la proporción que representa la masa salarial de la rama "i" en relación al total en el año "t". Por su parte $p_{i t}$ se refiere a la proporción que representa el empleo en esa rama en relación al total en el año "t".

Valores de este índice cercanos a cero indican mayor igualdad.

Finalmente, para saber la procedencia de los cambios en los salarios promedio e inferir a partir de esta descomposición la influencia de los ajuste en el salario mínimo, se descompuso el crecimiento del salario promedio nominal en tres componentes: uno de ellos ligado a los cambios en el empleo, otro ligado a los cambios en el salario nominal promedio y un componente de variación conjunta. Para ver en detalle este procedimiento consúltese el anexo 1 .

\section{Salarios mínimos y desigualdad salarial}

Para mejor comprensión de la temática, se parte de una breve descripción del empleo en El Salvador y de la estimación de un índice de concentración de este empleo, lo cual es relevante dado que el salario mínimo atiende a la rama de actividad en la que se genera este empleo. Posteriormente se describen las tarifas de salario mínimo y los

\footnotetext{
${ }^{11}$ Además de satisfacer la condición de Pigou-Dalton, cumple también la condición de cambio relativo, es decir, que es más sensible respecto a los cambios entre los valores extremos. Véase Cortés y Rubalcava (1984: 94).
} 
salarios promedio; y finalmente se estima el grado de desigualdad en la distribución de la masa salarial y se señala la influencia del salario mínimo en este aspecto.

\section{Distribución del empleo en los sectores secundario y terciario}

En este punto debe señalarse que el número de personas cotizantes al ISSS constituyen el universo de personas asalariadas sobre las cuales se tiene control institucional de cumplimiento del salario mínimo, ya que estas personas asalariadas tienen un contrato y pueden efectivamente demandar el cumplimiento del salario mínimo para la actividad en la que se desempeñan. Por esta razón es comprensible que, en todo el período de estudio, de cada cien personas cubiertas por el ISSS en la zona urbana, 90 sean asalariadas permanentes o temporales. Además, la categoría ocupacional Asalariados permanentes en la zona urbana es la que tiene una mayor proporción de personas cubiertas por el ISSS: de cada cien personas asalariadas permanentes, 77 están cubiertas por el ISSS (ver anexo 2). No obstante, debe tenerse en cuenta que el ISSS tiene baja cobertura en relación a la Población Económicamente Activa (PEA) ocupada, especialmente si esa cobertura se refiere a cotizaciones activas (24\% de PEA cotiza, en promedio, para el periodo).

Las anteriores acotaciones sirven para reiterar que este trabajo se refiere al impacto del salario mínimo sobre la desigualdad salarial, la cual será aplicable al universo de personas asalariadas que efectivamente pueden ejercer su derecho a un salario mínimo constitucionalmente establecido y tutelado por las instituciones pertinentes. Además, estas acotaciones son útiles para matizar la relación que tiene la distribución salarial respecto a la distribución del ingreso en El Salvador.

Por tanto, la pregunta sobre qué sentido tiene estudiar la desigualdad salarial en un país donde el empleo con cotización no es la forma más generalizada de ocupación, es pertinente. Desde la perspectiva de esta investigación, explorar cómo se distribuye la masa salarial entre las personas que laboran en las diferentes actividades productivas tiene relevancia porque ofrece indicios sobre los orígenes de la desigualdad en la distribución del ingreso, ya que esta puede originarse desde el ámbito del trabajo asalariado o desde otros ámbitos de la producción y distribución de la riqueza. También arroja información sobre el vínculo que guarda la estructura productiva con la estructura de empleo, de remuneraciones y la distribución del ingreso.

Por otra parte, se consideró importante ilustrar la composición del empleo de acuerdo al sector de la actividad económica en la que se ubica, dado que las tarifas salariales mínimas atienden a este criterio, es decir, el criterio respecto a la actividad económica en la que se inscribe el empleo. El gráfico 1 ilustra la importancia relativa de cada sector en lo referente al número de personas cotizantes registradas en las actividades propias de cada uno. Juntos, estos dos sectores aportan el $97 \%$ de todo el empleo registrado por el ISSS. Puede constatarse, además, la relevancia del sector terciario como fuente de empleos y como el principal generador de nuevos empleos, ya que mientras la generación de empleos en el sector secundario ha sido muy modesta e incluso negativa en algunos años; el empleo en las actividades terciarias ha crecido en casi todos los años del periodo, tal como lo muestra el gráfico 2 . 
Gráfico 1

Número de personas empleadas en sector secundario y terciario

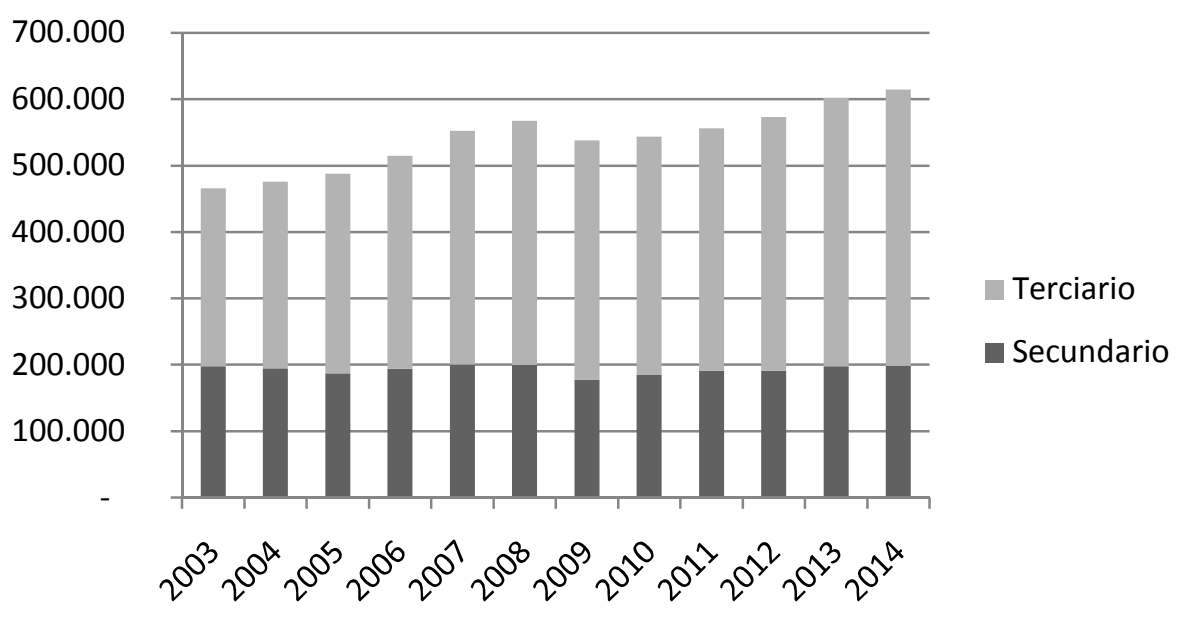

Fuente: elaboración propia en base a datos de ISSS sistematizados por Barrera y Valle (2015)

Gráfico 2

Nuevos empleos generados cada año, según sector económico

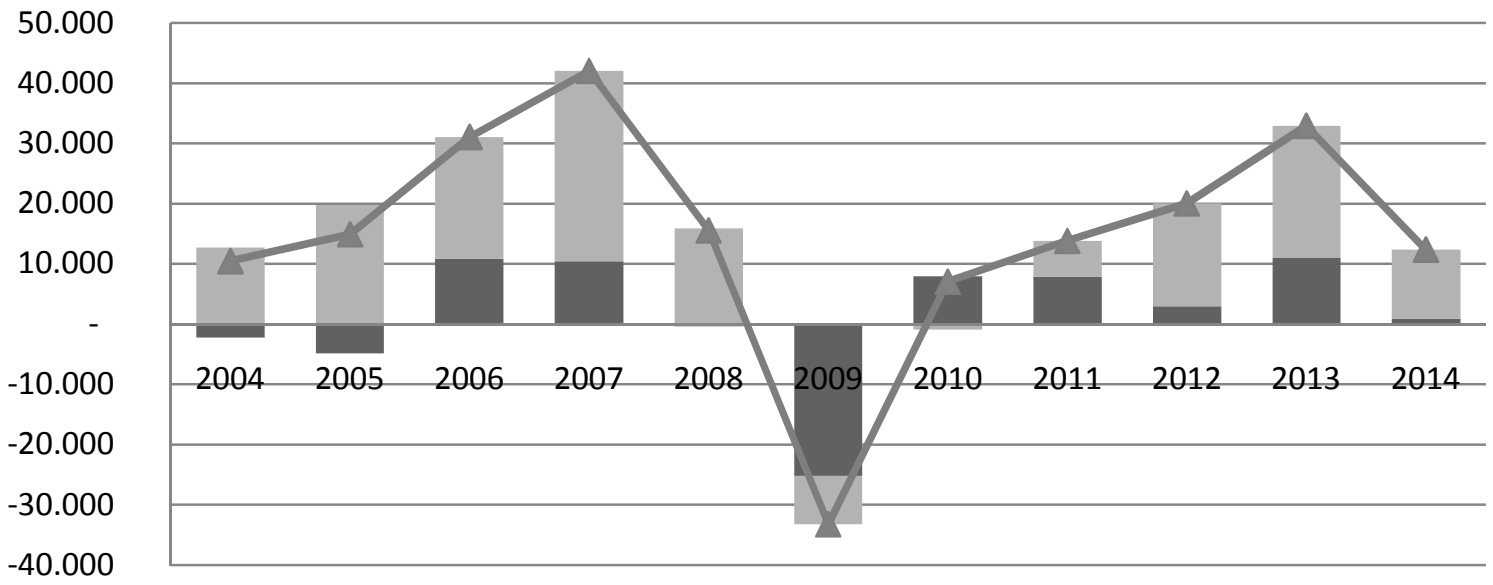

Nuevos empleos secundario Nuevos empleos terciarios $\longrightarrow$ Nuevos empleos totales

Fuente: elaboración propia en base a datos de ISSS sistematizados por Barrera y Valle (2015)

Esta mayor generación de empleos en las actividades terciarias implica que los salarios en esas actividades tienen más peso en los salarios promedio de las personas cotizantes de todo el sector privado.

Por otra parte, se constata que los empleos en cada sector tienen una concentración de alta a moderada entre las diferentes actividades económicas que los componen. Una muestra de ello es que más del $65 \%$ del empleo generado por las actividades secundarias y terciarias se concentra en 6 actividades económicas, es decir, $67 \%$ del 
empleo concentrado en el $22 \%$ de las actividades. Esta concentración se ha reducido en el periodo de este estudio, pero aún se mantiene en el rango de moderada concentración. Así lo muestra el Indice de Herfindahl y Hirschmann calculado para la distribución del empleo en cada sector y cuyo valor se presenta en el gráfico 3.

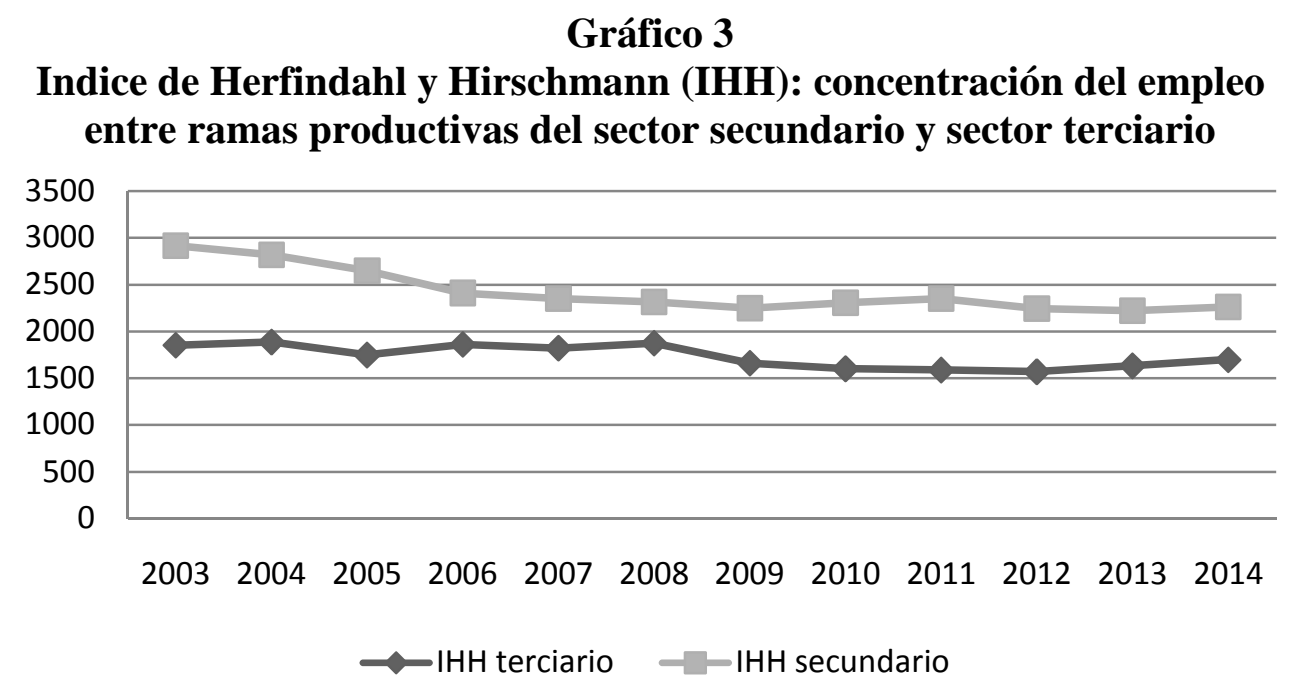

Fuente: elaboración propia en base a datos de ISSS sistematizados por Barrera y Valle (2015)

Tal como se muestra, en el periodo 2003-2005, el sector secundario tuvo alta concentración del empleo ( $\mathrm{HHH}>2500$ ). En los siguientes años se ubica en la zona de moderada concentración $(1500<\mathrm{IHH}<2500)$, en la cual ha permanecido también el empleo en el sector terciario en todo el periodo. Este proceso de relativa desconcentración del empleo en ambos sectores durante este periodo es un elemento a considerar al abordar la dinámica que ha tenido la distribución de la masa salarial, la cual se explorará a continuación.

\section{Salario mínimo y salario promedio}

El salario mínimo en El Salvador está reconocido como derecho en la constitución de la República en su artículo 38 inciso segundo, el cual establece que:

"Todo trabajador tiene derecho a devengar un salario mínimo, que se fijará periódicamente. Para fijar este salario se atenderá sobre todo al costo de la vida, a la índole de la labor, a los diferentes sistemas de remuneración, a las distintas zonas de producción y a otros criterios similares. Este salario deberá ser suficiente para satisfacer las necesidades normales del hogar del trabajador en el orden material, moral y cultural.” (Constitución de la República de El Salvador, artículo 38 inc. $2^{\circ}$ )

Los ajustes a este salario mínimo son aprobados por la Asamblea Legislativa una vez que son propuestos por el Consejo Nacional del Salario Mínimo, el cual es una instancia tripartita que tiene representación gubernamental, de la empresa privada y de las personas trabajadoras. Para esta investigación se considerarán únicamente los ajustes al salario mínimo correspondientes al periodo 2003-2014, los cuales se recogen en la siguiente tabla 1, en cuyos datos se puede verificar que el crecimiento acumulado de la tarifa de salario mínimo nominal vigente desde enero 2014 respecto a la tarifa vigente a 
partir de junio 2003 ha sido de un 53\% para Comercio y Servicios e Industria manufacturera; y de un 34\% en la Maquila textil y de la confección.

Tabla 1

Tarifas de salario mínimo aprobadas por Asamblea Legislativa de El Salvador 2003-2014. Dólares nominales por persona al mes

\begin{tabular}{|c|c|c|c|c|}
\hline $\begin{array}{l}\text { Fecha de entrada } \\
\text { en vigencia }\end{array}$ & $\begin{array}{l}\text { Comercio } \\
\text { y Servicios }\end{array}$ & $\begin{array}{c}\text { Industria } \\
\text { manufacturera }\end{array}$ & $\begin{array}{l}\text { Maquila textil } \\
\text { y confección }\end{array}$ & Decreto legislativo \\
\hline 01/ junio/ 2003 & $\$ 158.4$ & $\$ 154.8$ & $\$ 151.2$ & $\begin{array}{l}\text { Decreto } 37 . \mathrm{DO} \mathrm{N}^{\circ} 93 \text { Tomo } \\
\text { 359. 23/mayo/2003. }\end{array}$ \\
\hline 01/ sept./2006 & $\$ 154.30$ & $\$ 170.4$ & $\$ 157.2$ & $\begin{array}{l}\text { Decreto 83. DO N }{ }^{\circ} 156 \\
\text { Tomo } 372.24 / \text { agosto/2006 }\end{array}$ \\
\hline 15/ nov./2007 & $\$ 183.00$ & $\$ 179.1$ & $\$ 162.00$ & $\begin{array}{l}\text { Decreto 108. DO N }{ }^{\circ} 207 \\
\text { Tomo 377. 07/Nov./2007 }\end{array}$ \\
\hline 16/junio/ 2008 & $\$ 192.3$ & $\$ 188.1$ & $\$ 167.1$ & $\begin{array}{l}\text { Decreto } 64, \mathrm{DO} \mathrm{N}^{\circ} 100 \\
\text { Tomo } 379.30 / \mathrm{mavo} / 2008 \text {. }\end{array}$ \\
\hline 01/ enero/2009 & $\$ 207.6$ & $\$ 203.1$ & $\$ 173.7$ & $\begin{array}{l}\text { Decreto 135. DO N }{ }^{\circ} 241 \\
\text { Tomo } 381.22 / \text { dic. } / 2008\end{array}$ \\
\hline 16/ mayo/ 2011 & $\$ 224.1$ & $\$ 219.3$ & $\$ 187.5$ & $\begin{array}{l}\text { Decreto } 56 . \mathrm{DO} \mathrm{N}^{\circ} 85 \\
\text { Tomo } 391.06 / \mathrm{mayo} / 2011\end{array}$ \\
\hline 01/ julio/ 2013 & $\$ 233.1$ & $\$ 228.0$ & $\$ 195.0$ & $\begin{array}{l}\text { Decreto 104. DO N }{ }^{\circ} 119 \\
\text { Tomo 400. 01/julio/2013 }\end{array}$ \\
\hline 01/enero/ 2014 & $\$ 242.4$ & $\$ 237.0$ & $\$ 202.8$ & $\begin{array}{l}\text { Decreto 104. DO N }{ }^{\circ} 119 \\
\text { Tomo 400. 01/julio/2013 }\end{array}$ \\
\hline
\end{tabular}

Fuente: Elaboración propia en base a Diarios Oficiales (DO), varios años.

Por su parte, los salarios nominales promedio del sector secundario y del sector terciario se detallan en la tabla 2.

Tabla 2

Salario nominal promedio mensual en sector secundario y sector terciario 20032014. En dólares por persona

\begin{tabular}{|c|c|c|}
\hline Año & Sector secundario & Sector terciario \\
\hline 2003 & 299,20 & 335,23 \\
\hline 2004 & 302,69 & 335,65 \\
\hline 2005 & 312,29 & 341,73 \\
\hline 2006 & 327,12 & 365,45 \\
\hline 2007 & 342,30 & 389,69 \\
\hline 2008 & 358,05 & 406,76 \\
\hline 2009 & 383,17 & 411,33 \\
\hline 2010 & 400,34 & 419,65 \\
\hline 2011 & 411,77 & 422,91 \\
\hline 2012 & 425,10 & 435,46 \\
\hline 2013 & 432,71 & 442,44 \\
\hline 2014 & 445,16 & 450,73 \\
\hline
\end{tabular}

Fuente: Elaboración propia en base a datos ISSS sistematizados por Barrera y Valle (2015) 
En lo relativo al monto de las remuneraciones nominales promedio, destaca una estructura similar en los puntos extremos del período (2003 y 2014). Ordenados de manera ascendente de acuerdo al salario medio nominal mensual; y comparando los puntos extremos del periodo de estudio, se puede identificar cuáles actividades económicas empeoraron su posición en relación a otras en lo referente al salario medio nominal que pagan. Esta información se presenta en el anexo 3.

Entre las ramas económicas que mejoraron su posición en relación al salario promedio nominal están: Textiles, prendas de vestir e industria del cuero, Otras industrias manufactureras, Manufacturas de madera, artículos de madera y mueblería; Inmobiliarias y servicios a los negocios; Manufactura de productos de metal fabricados, maquinaria y equipo; Transporte y almacenamiento; Manufacturas de papel, productos de papel, impresión y publicidad y, finalmente, Actividades financieras.

Las ramas cuya posición desmejoró son: Restaurantes y hoteles; Servicios personales y a los hogares; Comercio al por menor; Construcción; Recreación y servicios culturales; Servicios comunitarios y sociales; Manufactura de productos de minerales no metálicos excluyendo productos de petróleo y caucho; y Administración pública y defensa.

Sin embargo, más allá de las actividades económicas particulares que se ubican por debajo y por encima de la mediana ${ }^{12}$, el porcentaje de personas cotizantes ubicadas en la franja inferior a la mediana creció entre esos dos puntos del tiempo, tal como se muestra en el gráfico 4.

\section{Gráfico 4}

\section{Distribución del empleo en los sectores secundario y terciario de acuerdo a} monto de salarios en relación a la mediana

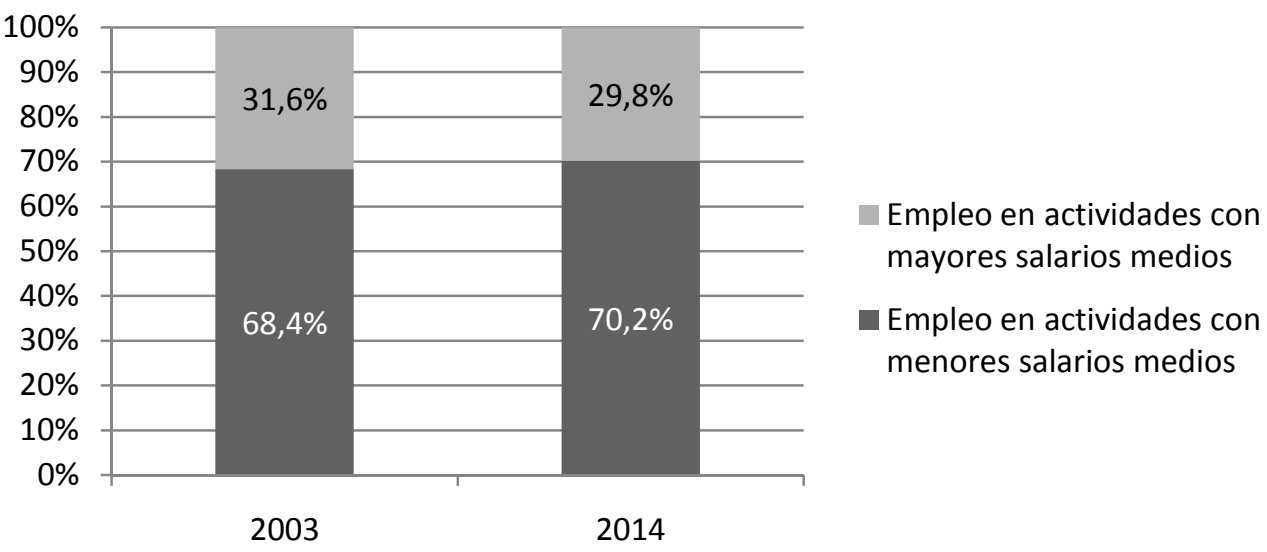

Fuente: elaboración propia en base a datos de ISSS.

Por otra parte, la proporción que representan los salarios medios más altos en relación a los más bajos ${ }^{13}$ se ha reducido en los puntos extremos del periodo: en 2003 el salario mayor era casi 5 veces mayor al inferior; mientras que en 2014, era casi 3 veces mayor. Esta reducción en la distancia resulta del menor crecimiento de los salarios mayores en

\footnotetext{
${ }^{12}$ Se toma como la mediana un monto de $\$ 324.22$ para el año 2003; y $\$ 464.18$ para 2014. Estos salarios se estimaron como el promedio simple de los salarios correspondientes a las posiciones 12 y 13 del listado en la tabla 1. Ello es posible porque las actividades están ordenadas ascendentes de acuerdo al salario promedio que pagan.

${ }^{13}$ En este caso, se hace referencia al salario medio de la actividad Servicios de saneamiento y similares, que es el más bajo; y se relacionó con el salario medio de la actividad Electricidad, gas y vapor, que es el más alto. Se excluyó la actividad Organizaciones Internacionales porque la determinación de esos salarios está influenciada por criterios propios de estas organizaciones, los cuales trascienden las fronteras nacionales.
} 
concomitancia con un crecimiento más pronunciado de las tarifas inferiores. Esto último puede estar ligado a los ajustes al salario mínimo y su afectación sobre aquéllos sectores cuyas remuneraciones rondan esos valores.

Visto a través de la dispersión entre las remuneraciones promedio de las personas de cada actividad productiva al interior del sector secundario y del sector terciario, se verifica que ésta se ha reducido en 2014 respecto a 2003 en ambos sectores. Ello sería indicativo de un mayor acercamiento de las remuneraciones promedio de las diferentes ramas. Así por ejemplo en 2003, la dispersión estándar entre los salarios medios de las distintas actividades del sector secundario y terciario era de $\$ 153.56$ y $\$ 152.11$ respectivamente. Para 2014, la dispersión se redujo tanto en el sector secundario, con una magnitud de \$125.26; como en el sector terciario, con dispersión de \$144.78.

Por su parte, la proporción que representan los salarios mínimos respecto al salario nominal medio registrado en las diferentes ramas productivas muestra que el salario mínimo tiene un peso importante comparado con las remuneraciones promedio (ver anexo 4). Para algunas actividades, esta proporción es mayor al 70\%. Esto último sería indicativo de que la mayor parte de personas empleadas en esas ramas productivas gana salarios que rondan la tarifa mínima. En otras palabras, ha ocurrido una mayor compresión de los salarios promedio entre ramas productivas, ya que se han aglutinado el estrato de menores remuneraciones. Esto se confirma al estimar los indicadores de desigualdad propuestos.

\section{Medición del grado de desigualdad salarial}

El índice de Gini suele ser el más utilizado para estimar el grado de desigualdad en la distribución de una variable. Al realizar este cálculo con los datos disponibles se obtiene un resultado llamativo: según este índice, la distribución de la masa salarial entre las ramas productivas es casi perfectamente equitativa, tal como se muestra en el gráfico 5.

\section{Gráfico 5 \\ Evolución de Índice de Gini de la distribución de la masa salarial en sector secundario y terciario}

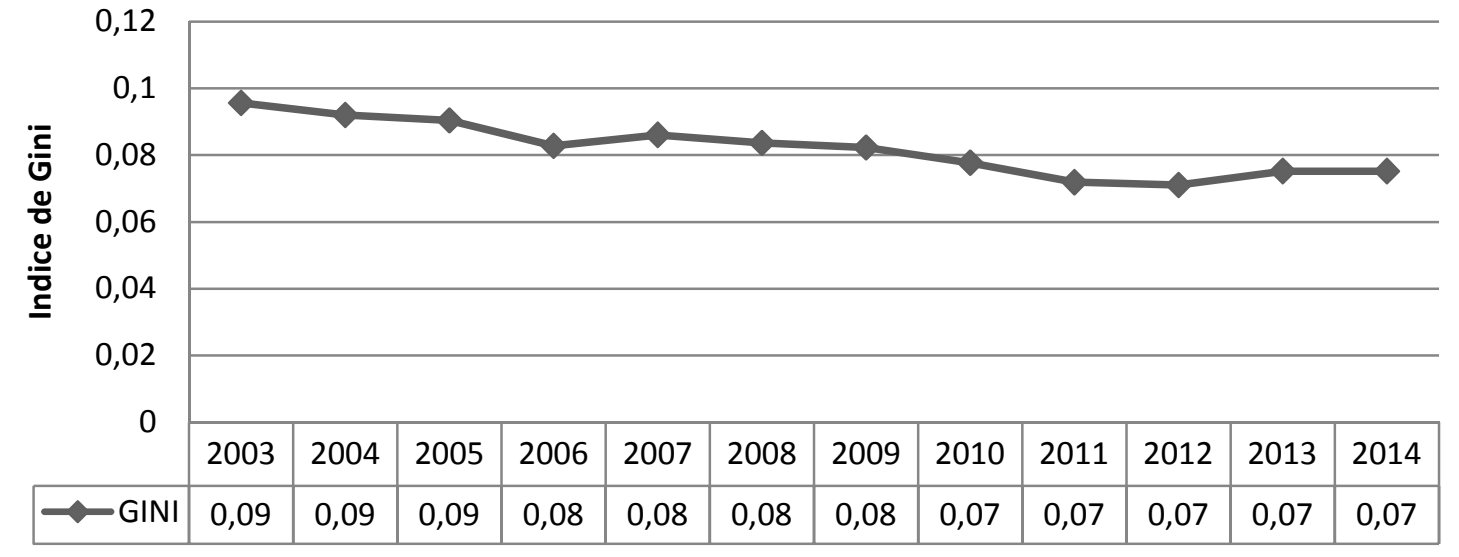

Fuente: Elaboración propia con datos de ISSS sistematizados por Barrera y Valle (2015)

A partir de lo que muestra el gráfico 5 puede inferirse que la desigualdad en la distribución de la masa salarial no es un problema por el cual preocuparse. Esto, a la luz 
de los niveles de los salarios promedio de los sectores descritos anteriormente, es un indicio de que el problema con la masa salarial no es tanto cómo se distribuye, sino más bien su monto, que constituye una parte pequeña del ingreso total producido ${ }^{14}$.

Otro indicador de concentración que es apropiado estimar es el índice entrópico de Theil que, según Rubalcaba y Cortés (1982: 94), es más confiable en relación a la información arrojada por el índice de Gini. Para la distribución salarial utilizada en esta investigación, el resultado obtenido con este índice (Theil) es consistente con el resultado arrojado por el índice de Gini, tal como lo ilustra el gráfico 6.

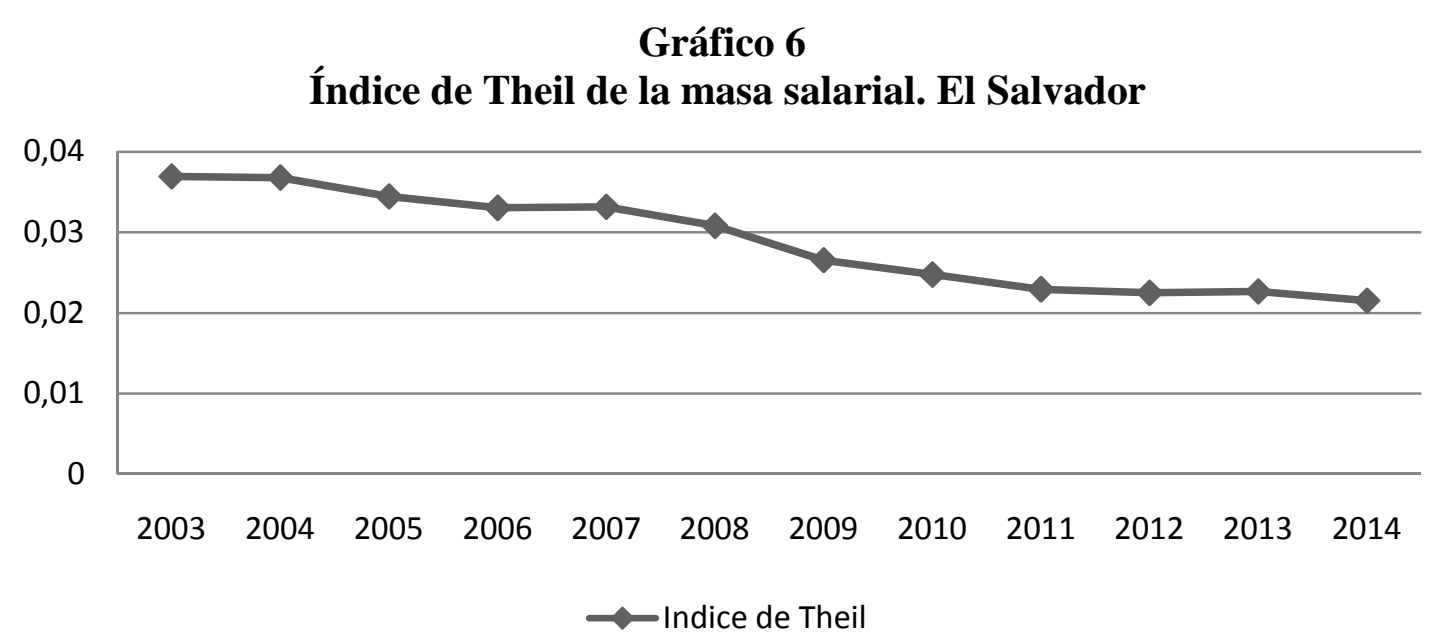

Fuente: Elaboración propia

Como se constata, el valor de este índice para la distribución de salarios en El Salvador es casi cero y además es decreciente, lo cual es indicativo de una distribución bastante equitativa que, tiende a acentuarse en los últimos años. Además, es destacable que el descenso de este índice es más pronunciado que el correspondiente al índice de Gini, lo cual indica que las posiciones más altas en cuanto a salarios promedio han transferido importancia a las de más baja posición. Esta transferencia se puede originar por cambios en la participación en el empleo total o por un crecimiento más lento de las remuneraciones promedio más altas.

Puestas así las cosas, resta explorar cuál es el papel que el salario mínimo juega en esta dinámica de la distribución de la masa salarial. Y, para ello, un primer indicador es la proporción que el salario mínimo representa respecto del salario promedio de cada sector. El gráfico 7 ilustra la evolución del peso del salario mínimo en relación a las remuneraciones promedio tanto para el sector secundario como para el terciario, en el periodo 2003-2014. Como se muestra, el peso del salario mínimo sobre el salario medio $^{15}$ en el sector secundario, ha decrecido a lo largo del periodo de estudio. Esta pérdida relativa de importancia coincide con un descenso en el número de personas empleadas en actividades donde este peso es alto, como el caso de las actividades textiles, en las que el salario mínimo representaba el $60 \%$ del salario medio de la rama; y esta a su vez, aportaba $49 \%$ de las personas empleadas en todo el sector secundario en

\footnotetext{
${ }^{14}$ Las estimaciones a este respecto pueden hacerse usando datos de la producción medida a costo de factores en la Matriz Insumo Producto (MIP) de El Salvador. No obstante, la última MIP que incluye esta información es la de 1990. En ella se estimaba que del valor agregado producido, solo el 32,53\% correspondía a remuneraciones al trabajo (Ibisate, 19945: 312).

${ }^{15}$ Esta proporción se ha ponderado por el peso relativo de cada actividad productiva en el empleo del sector en el que se ubica. Estos pesos relativos pueden corroborarse en el anexo 3.
} 
2003. Hoy esta rama ha perdido importancia, aunque aún sigue siendo la más importante de la Industria y de todo el sector secundario (ver anexo 3).

\section{Gráfico 7 \\ Proporción que representa el salario mínimo respecto al salario medio nominal de acuerdo a Sector económico}

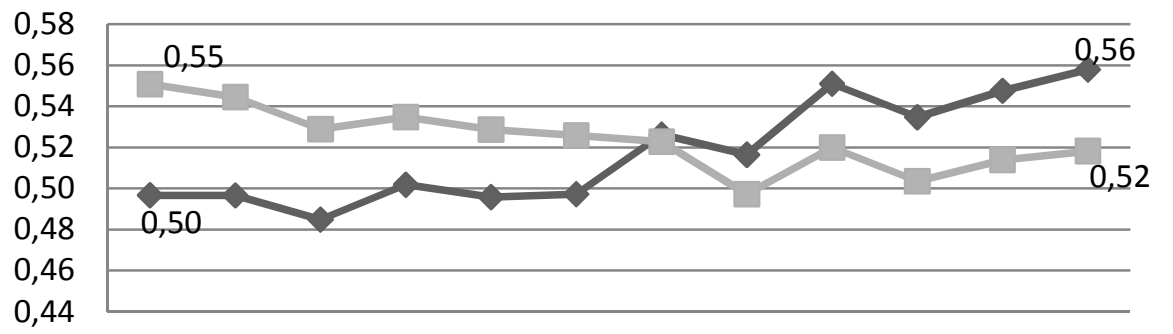

200320042005200620072008200920102011201220132014

$\multimap$ Sector terciario $\rightarrow$ Sector secundario

Fuente: elaboración propia.

Para el caso del sector terciario, el comportamiento de este peso es justamente el contrario al mostrado por el sector secundario, es decir, el peso del salario mínimo en relación al promedio ha crecido a lo largo del período de estudio. Es más, en todas las actividades del sector terciario esta proporción es mayor en 2014 en relación a 2003. Y esto no solamente es válido para esta proporción, sino también para la generación de empleos, ya que mientras la generación de empleos en el sector secundario está estancada, las actividades terciarias han incrementado su participación como fuente de empleo, como ya se mostró anteriormente.

Ahora bien, si el salario mínimo es creciente en términos nominales y el empleo también es creciente en esas actividades, se tiene un elemento que cuestiona de manera importante lo que cabría esperar de acuerdo a la visión convencional sobre los efectos del salario mínimo sobre el empleo: mayor salario, menor empleo. Los señalamientos de FUSADES (2010: 39) en este sentido, es decir, en la relación entre incrementos en el salario mínimo y la generación de empleos, visto de manera prospectiva, apoyan esta última visión ${ }^{16}$. Sin embargo, la generación de empleos con cotización ha sido positiva en todos los años, excepto en 2009; y en el mismo periodo los salarios mínimos reales han crecido, aunque en pequeña cuantía (ver anexo 5). Esto es especialmente cierto en el sector terciario, el cual, como ya se mostró, tiene las tarifas más altas de salario mínimo y, además, es la tarifa que más ha crecido en términos nominales, junto con la tarifa correspondiente a Industria manufacturera.

\footnotetext{
16“"Los resultados muestran que cuando incrementa el salario mínimo, se reduce la probabilidad de mantener el empleo después del cambio en el sector cubierto privado para trabajadores permanentes, y aumenta la probabilidad de mantenerse como empleado temporal [...] También, se reduce la probabilidad de conservar la cotización al sistema de salud del Instituto Salvadoreño del Seguro Social (ISSS), lo cual está correlacionado con empleos formales en empresas grandes, en tal sentido, el aumento en el [salario mínimo] genera una precarización en el mercado laboral.” (FUSADES, 2010: 39)
} 
Por otra parte, el salario mínimo nominal correspondiente a Maquila textil y confección es el menor en términos absolutos y el que menos ha crecido en el periodo (incluso su salario mínimo real ha sido descendiente, ver anexo 5); y simultáneamente el empleo en esta rama productiva ha descendido en términos absolutos en el mismo periodo.

El recuadro 1 muestra las correlaciones que indican que la relación entre empleo y salarios mínimos reales no ha ocurrido en la dirección prevista por la visión convencional. Tal como se muestra, la correlación es positiva, con un coeficiente de correlación lineal por encima de 0.69. Además, las ecuaciones de la las líneas de tendencia explican más del $48 \%$ de las variaciones, según el coeficiente de determinación.

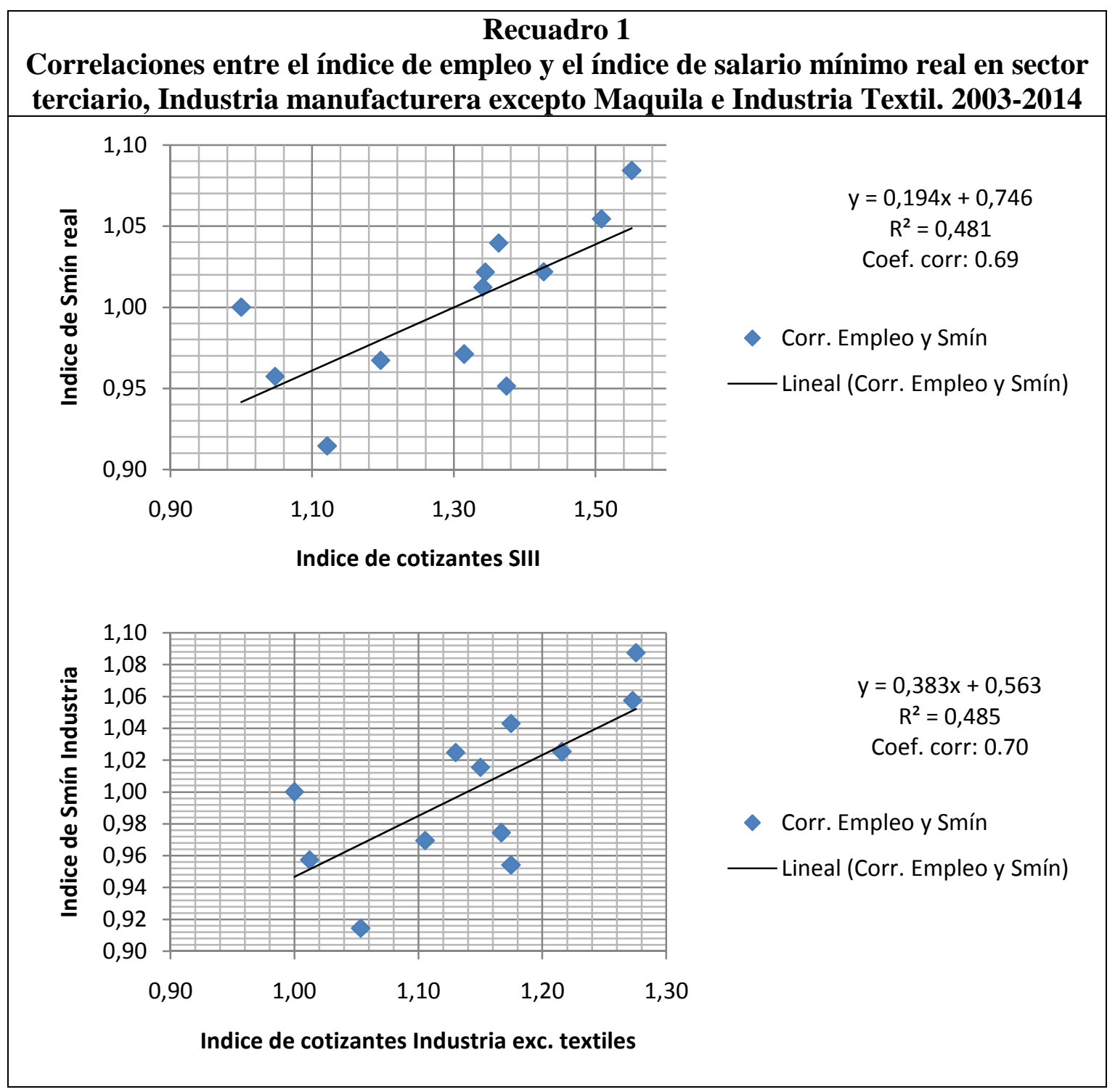




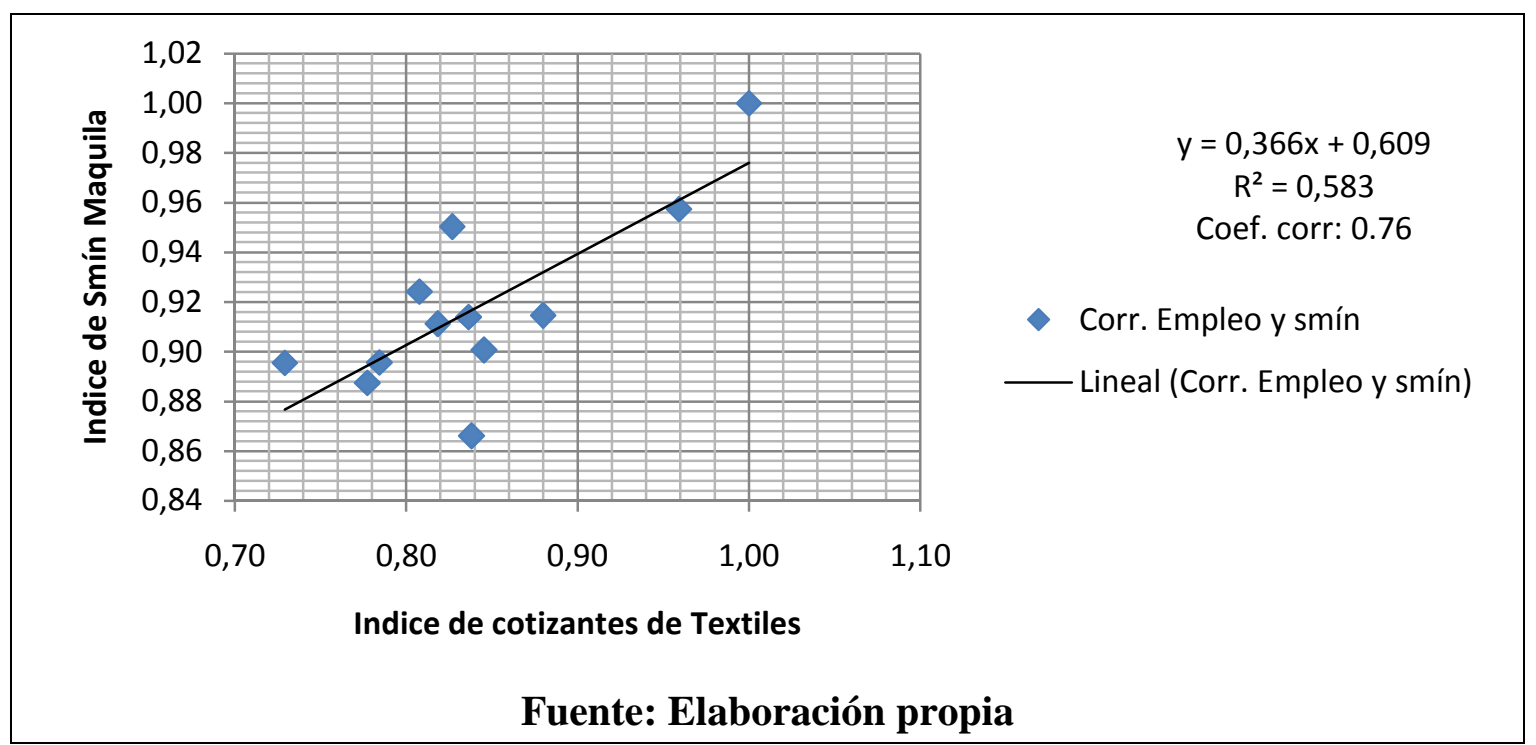

Con estos elementos, se infiere que las variaciones en el volumen de empleo pueden no ser determinadas en una medida significativa por la tarifa de salario mínimo correspondiente. Hay otros elementos que deben considerarse en las variaciones en el empleo, entre ellos se encuentran las condiciones más o menos favorables que las actividades económicas en cuestión enfrentan: precios externos de insumos y de productos a la venta, volumen de exportaciones, volumen de ventas en mercado interno, rentabilidad presente y esperada, por ejemplo.

En última instancia, hay razones de peso para considerar que lo que Maurizio (2014: 8) denominó efecto truncamiento (mejora en salario promedio por reducción del empleo con menores salarios por incremento de salario mínimo), es parcialmente válido para el caso salvadoreño. Los datos muestran que ha ocurrido un proceso parecido al efecto truncamiento en algunas actividades industriales, aunque las razones pueden no obedecer necesariamente a los ajustes en el salario mínimo, como es el caso de las actividades textiles y de la confección ${ }^{17}$.

En las actividades terciarias, dado el peso creciente del salario mínimo respecto al salario medio, puede inferirse que las personas que se están incorporando en las actividades terciarias ganan el mínimo o muy cerca de ese monto, de tal forma que la importancia de esta tarifa respecto a la remuneración promedio, crece en el tiempo a medida que también crece el número de personas incorporadas en estas actividades.

Ahora bien, no es posible verificar con los datos disponibles, que de no haberse incrementado el salario mínimo se habrían generado más empleos de los que se han

\footnotetext{
${ }^{17}$ Según Barrera (2015: 150-151 y 186) la mejora en el salario promedio real cotizable en la industria manufacturera salvadoreña, que pasó de $\$ 416.8$ a $\$ 473.1$ de 2003 a 2011 ; se ha debido a la sensible pérdida de empleos en la industria de la maquila textil, que es la rama que tiene la menor tarifa de salario mínimo a nivel urbano y a su vez, la que aporta la mitad de cotizantes de toda la industria. Pero, aún cuando esa pérdida de empleos coincide con incrementos en las tarifas de salario mínimo, no puede afirmarse de manera contundente que la reducción de empleos se debió a esos incrementos, los cuales han sido más bajos que los incrementos del resto de salarios mínimos urbanos; sino más bien hay que considerar las dificultades que enfrentó esta rama de actividad una vez abiertas las fronteras estadounidenses a las exportaciones textiles de Asia, lo cual redujo las ventas de textiles maquilados en El Salvador en su principal mercado que es Estados Unidos.
} 
generado en concomitancia con los incrementos. Eso es algo que no se podría afirmar de manera contundente salvo opinión expresa del sector empresarial en cuanto al cambio en su intencionalidad de contratar a más personas debido a incrementos en salario mínimo, lo cual escapa al alcance del presente trabajo.

Por otra parte, si los movimientos ocurren tanto en el empleo como en las remuneraciones nominales, es preciso mostrar cómo afecta uno y otro movimiento a las variación final de las remuneración promedio del sector secundario y del sector terciario, ya que las variaciones absolutas en el empleo de cada rama de actividad, también cambia el peso que el empleo de esa rama tiene respecto a todo el sector y, por tanto, cambia su influencia sobre los indicadores sectoriales. Además, los cambios en el salario nominal promedio de cada rama de actividad pueden resultar de cambios en las tarifas de salario mínimo, o de recomposición interna con más personas en puestos mejor remunerados y menos personas en puestos peor remunerados. De lo segundo no se tiene indicios ni información, pero de las variaciones en el salario mínimo nominal, si.

Al descomponer las variaciones en los salarios promedio sectoriales, se obtienen los resultados que se presentan en los gráficos $8 \mathrm{a}$ y $8 \mathrm{~b}$. En ellos se presenta cuál es el aporte de las variaciones en la estructura de empleo de cada sector y las variaciones en los salarios nominales promedio de cada rama que integra el sector en cuestión; sobre las variaciones del salario nominal promedio de cada sector. Tal como se muestra, las variaciones en el salario nominal promedio de cada rama han tenido más incidencia en las variaciones del salario promedio nominal de cada sector. Por ejemplo, en el sector secundario, el salario promedio nominal mensual creció en \$14.83 en 2006 respecto a su monto en 2005; de estos, $\$ 11.38$ son atribuibles a cambios en las remuneraciones nominales promedio en las ramas de ese sector.

\section{Gráfico 8a}

Componentes de la variación en el salario promedio del Sector secundario. En dólares nominales mensuales.

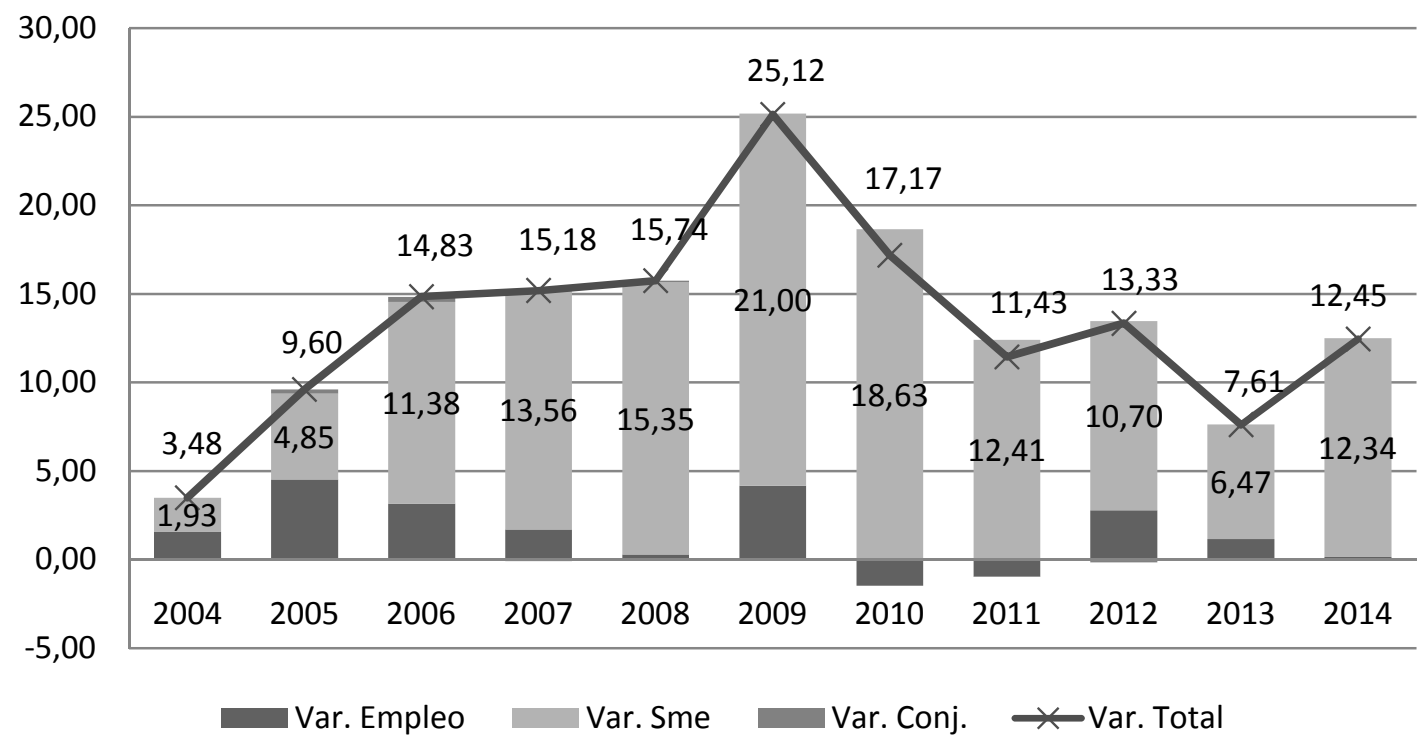

Fuente: Elaboración propia 


\section{Gráfico 8b \\ Componentes de la variación en el salario promedio del sector terciario. En dólares nominales mensuales.}

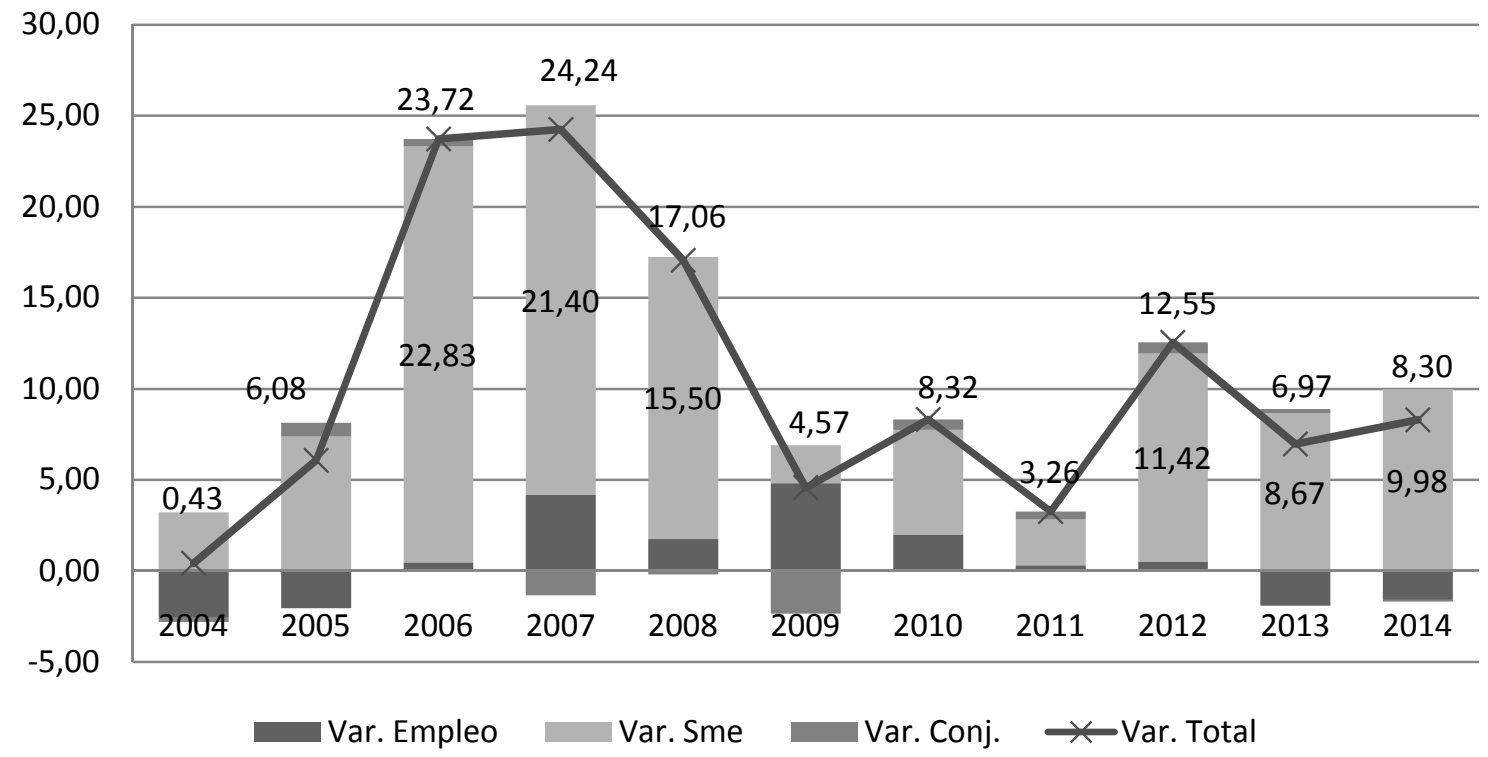

Fuente: Elaboración propia.

Este mayor dinamismo de las remuneraciones nominales promedio respecto al peso en el empleo obedece a que, si bien es cierto han ocurrido recomposiciones a nivel de empleo por sector económico (algunas ramas han ganado importancia en su sector y otras la han perdido), estas han sido de pequeña magnitud en relación a las variaciones ocasionadas por los salarios nominales. Estas variaciones en los salarios de cada rama obedecen tanto a incrementos en la tarifa mínima como a cambios en el perfil de salarios de los puestos que se generan: más puestos de trabajo con mejores remuneraciones nominales, mayor el incremento del salario promedio del sector. Esto último también ocurre cuando se pierden empleos con las menores remuneraciones.

En lo que respecta a esta investigación se considera que el aporte de los ajustes en el salario mínimo nominal en el periodo de estudio ha sido clave para el avance en el salario promedio de los sectores, especialmente si se considera que algunas ramas productivas en donde la tarifa mínima es más cercana con el salario promedio, han incrementado su participación en el empleo, con lo cual su influencia en los promedios sectoriales se acentúa. Esto es especialmente válido para las actividades terciarias.

Finalmente, considerando los niveles salariales y la evolución de estos tanto en términos nominales como reales, puede inferirse que la distribución más equitativa no necesariamente mejora la situación de las personas asalariadas, especialmente si ocurre debido a una progresiva erosión de las remuneraciones que superan la tarifa mínima, de tal forma que las tarifas mínimas se acercan cada vez más a los salarios promedio, ya que los salarios superiores a esta tarifa mínima crecen muy poco o no crecen; o crece menos el número de personas que gana estos salarios superiores. Esto último se ilustra en los gráficos 9a y 9b. En ellos se presenta la dinámica que ha seguido el salario mínimo real correspondiente a cada sector y el salario promedio real. Como se observa, el salario mínimo real fue descendiente en el sector secundario en los primeros 6 años del periodo y la dinámica del salario promedio no fue muy diferente. Solo posteriormente ocurre una tímida recuperación. 
Por su parte, en el sector terciario el salario medio real fue en lento pero continuo ascenso en los primero seis años, luego se ha estancado. La tarifa mínima ha estado estancada la mayor parte del tiempo, aunque muestra ascensos tímidos en los últimos cinco años. Así, las tarifas salariales mínimas se acercan progresivamente a las remuneraciones promedio en las actividades económicas urbanas, particularmente a las del sector terciario, y este proceso de acercamiento se acelera en la medida en que las remuneraciones superiores se rezagan más que la tarifa mínima o en la medida en que las personas que ganan el salario mínimo son más en términos absolutos o relativos.

\section{Gráfico 9a}

Índice de salario medio real en el sector secundario y de salario mínimo real en Industria y en Maquila Textil. 2003=100

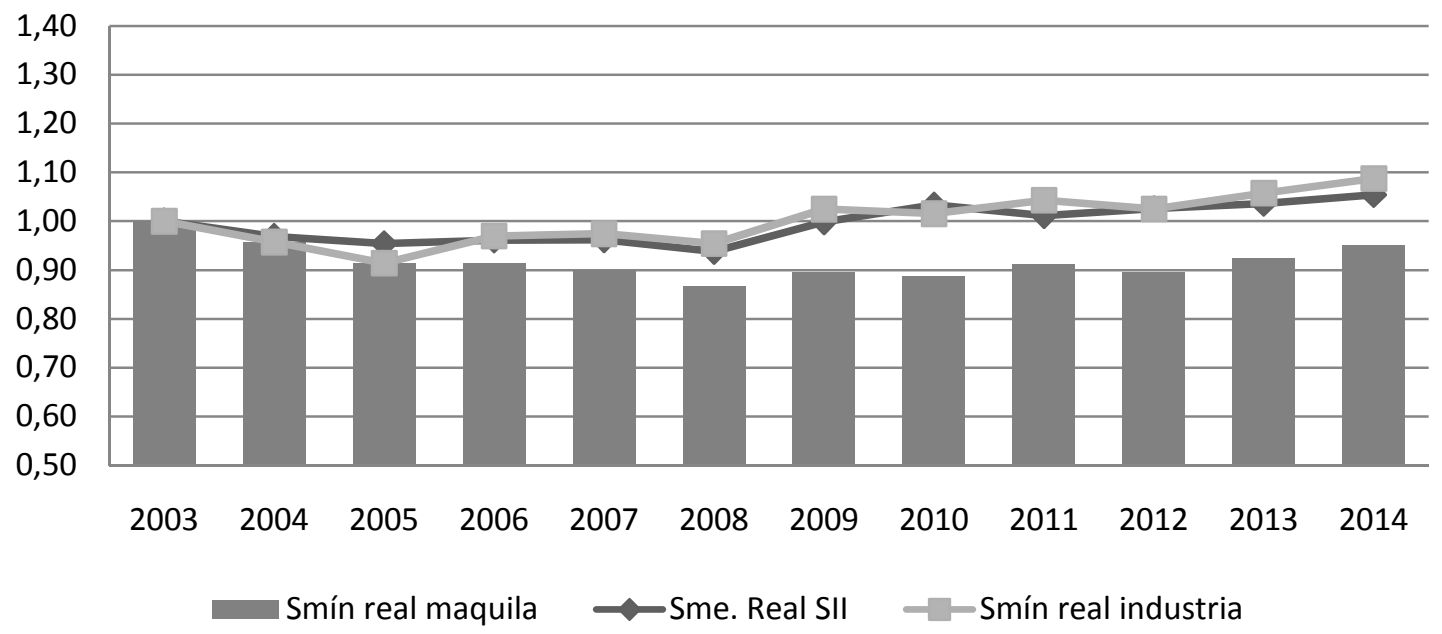

Fuente: elaboración propia

\section{Gráfico 9b \\ Índice de salario medio real en el sector terciario y de salario mínimo real en Comercio y servicios. 2003=100}

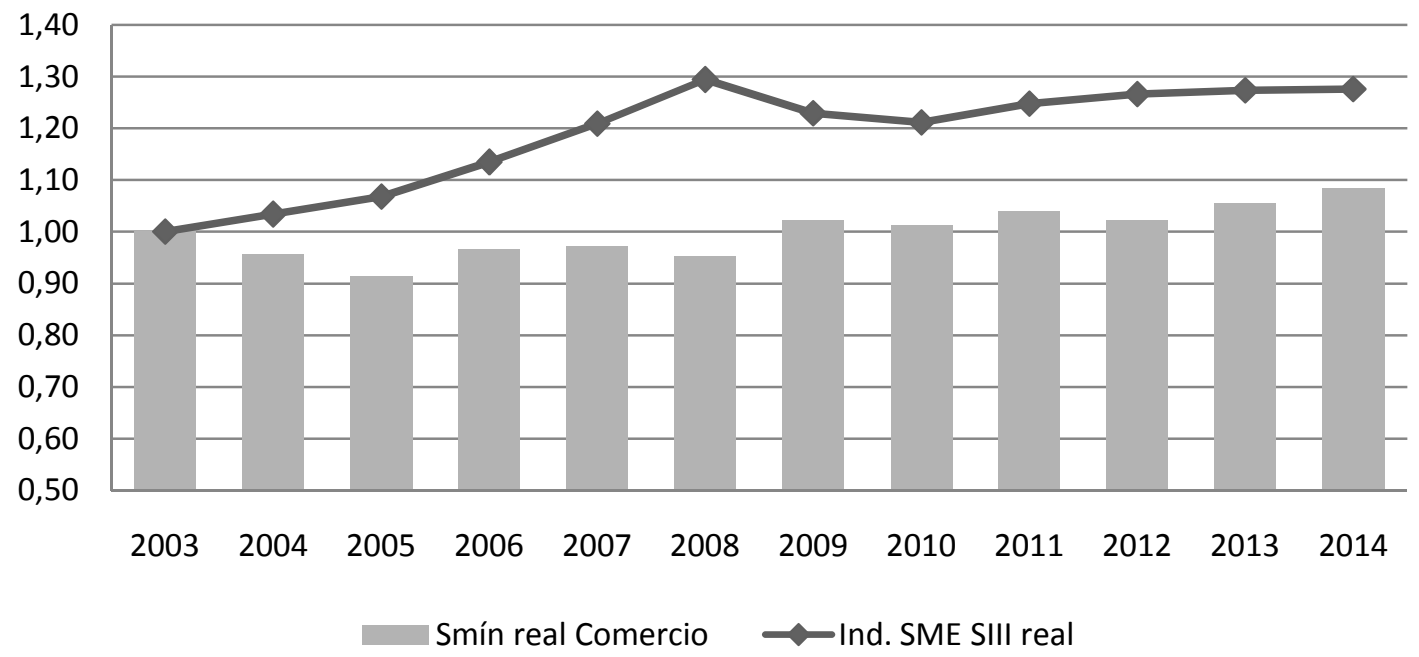

Fuente: elaboración propia. 
Los datos presentados previamente dan insumos para comprender la importancia de la tarifa mínima en la desigualdad salarial, aún cuando esta no sea un problema apremiante en términos agregados. En términos generales, puede afirmarse que en El Salvador ha ocurrido una compresión en los salarios en los estratos más bajos de remuneración y ello ha coincidido con un crecimiento más dinámico de los salarios promedio más bajos en relación a los más altos. Pero, para mayor comprensión del papel que juegan los salarios mínimos en la distribución salarial y en otros aspectos del empleo en El Salvador, se necesita contar con datos pormenorizados sobre los salarios asociados a los diferentes puestos de trabajo y las características individuales de las personas cotizantes. Con esta información sería posible tener conclusiones más contundentes respecto no solo al papel de los salarios mínimos sobre la desigualdad salarial, sino sobre el empleo y la estructura productiva del país. 


\section{Conclusiones}

La hipótesis de partida de este trabajo se evidenció como falsa dado que en El Salvador la desigualdad en la distribución de los salarios es baja y se ha reducido en el periodo de estudio. Por esta razón se afirma que el problema no radica en el grado de desigualdad en la distribución de la masa salarial, sino más bien en el nivel mismo de los salarios, lo cual es sintomático de la estrechez de esta masa salarial.

Además, a partir de los hallazgos se infiere que ha operado una "equiparación hacia abajo", es decir, los escasos progresos en el salario mínimo real ocurren en concomitancia con unos aún más escasos progresos de los salarios superiores al mínimo. Esto problematiza la noción de que un menor grado de desigualdad es bueno en sí mismo, ya que si los salarios se comprimen hacia abajo, se reduce el grado de desigualdad salarial, pero la distancia que separa a las personas empleadas de aquéllas que viven de otros ingresos (especialmente de rentas derivadas de actividades empresariales), se amplía, a menos que el descenso ocurra en todos los ingresos y no solo en los salarios; en cuyo caso también es cuestionable la conveniencia de un descenso en la desigualdad del ingreso.

Desde la perspectiva de esta investigación, la situación más favorable sería aquélla en la que ocurra un incremento en la masa salarial, es decir, que incremente "el tamaño del pastel" a repartirse entre las personas trabajadoras y que esta porción más grande, se reparta equitativamente, aunque como se mostró, la desigualdad no parece ser el problema más apremiante en lo que a distribución salarial se refiere.

Finalmente, se concluye que los salarios mínimos son un poderoso elemento de defensa del salario de una parte importante de las personas empleadas en El Salvador, especialmente en ciertas ramas productivas donde su incidencia es mayor. Y, por otra parte, lo negativo de sus ajustes en lo tocante al empleo (o lo conveniente de su estancamiento o reducción) no es verificable de manera retrospectiva, al menos con los datos reportados por el ISSS.

De esta manera, debe desecharse la idea de que el ajuste del salario mínimo (o su incremento eventualmente) es nocivo porque comprime los salarios en la parte más baja de la distribución y amenaza el nivel de empleo; más bien debe revisarse cuáles son los mecanismos que subyacen a los aumentos salariales en los tramos superiores al salario mínimo, de tal manera que se tenga más información sobre la política interna de las empresas en lo relativo a las remuneraciones, de lo contrario se corre el riesgo de que, al identificar a los incrementos al salario mínimo como la causa de un problema (en lugar de las políticas de estancamiento salarial a todo nivel) se estaría condenando al empobrecimiento progresivo a los estratos de empleados que reciben el salario mínimo y se constreñiría aún más la capacidad de demanda efectiva de la población empleada.

A manera de recomendación: para evaluar más en detalle el impacto del salario mínimo sobre el empleo, es necesaria alguna información sobre las características individuales de las personas cotizantes y de los establecimientos en los que laboran. Esto también sería útil para aislar el efecto del salario mínimo del efecto de reconfiguración de puestos al interior de las ramas de actividad sobre el salario promedio pagado en cada rama. Esto constituye una oportunidad para posteriores estudios. 


\section{Bibliografía}

Alaniz, Enrique; Gindling, T. y Terrell, Katherine (2011) "The impact of minimum wages on wages, work and poverty in Nicaragua" en Labour economics, volume 11, $\begin{array}{llllll}\text { supplement } & 1 & \text { pp. } & \text { S45-S59. } & \text { En }\end{array}$ http://www.iza.org/conference files/worldb2010/gindling t1592.pdf> Acceso $20 \mathrm{de}$ noviembre de 2015.

Arranz Muñoz, José y García Serrano, Carlos (2014) Evolución de la desigualdad salarial en los países desarrollados y en España en los últimos treinta años. VII Informe sobre exclusión y desarrollo social en España. Documento de trabajo 2.5. Fundación Foessa, en http://www.foessa2014.es/informe/uploaded/documentos_trabajo/15102014141550_577 6.pdf> Acceso 10 de octubre de 2015.

Banco Interamericano de Desarrollo, BID (1998) América Latina frente a la desigualdad en $<$ http://idbdocs.iadb.org/wsdocs/getdocument.aspx?docnum=35129836> Acceso 08 de octubre de 2015.

Barrera, Saira (2015) La ocupación en la industria manufacturera en El Salvador 1990-2011. Un análisis desde la teoría de la regulación. Tesis de maestría, Universidad Nacional Autónoma de México, UNAM.

Barrera, Saira y Valle, Lorena (2015) Base de datos de número de personas cotizantes y monto de salarios nominales pagados por rama productiva a cuatro dígitos de la CIIU revisión 2 y revisión 3. Inédito.

Becker, Gary (1983) "Inversión en capital humano e ingresos" en Toharia, Luis (Comp.) El mercado de trabajo: teorías y aplicaciones. Lecturas seleccionadas. (Madrid, Alianza editorial, páginas 39-64).

Boike, Rehbein. y Guidetti, Giovanni (2014) “Theoretical Approaches to Inequality in Economics and Sociology. A preliminary assessment" en Transcience Vol. 5 Issue 1 en $<$ http://www2.hu-berlin.de/transcience/Vol5_No1_2014_1_15.pdf $>$ Acceso 16 de diciembre 2015.

Bolaños, Francisco; Góchez, Roberto y Salgado, Melissa (2010) Los determinantes estructurales de la evolución de los flujos comerciales entre El Salvador (ES) y la Unión Europea (EU) en <http://library.fes.de/pdf-files/bueros/fesamcentral/08487.pdf $>$ Acceso 25 de febrero 2016.

Carrillo-Huerta, Mario y Vázquez Mateos, Haidee (2005) "Desigualdad y polarización en la distribución del ingreso salarial en México" en Problemas del Desarrollo Revista Latinoamericana de Economia Vol. 36 Número 141, UNAM, México. En < http://www.redalyc.org/articulo.oa?id=11820075007> Acceso 15 de octubre de 2015.

Chamorro, Jessica y Ramos, Joseph (2013) "Salario mínimo, lo técnico y lo valórico" en Trabajos de Investigación en Políticas Públicas $\mathrm{N}^{\circ} 18$ Noviembre 2013. Departamento de Economía, Universidad de Chile en < http://www.econ.uchile.cl/uploads/publicacion/a9aa4f21db2ce37d7a3e30798dd195f711 4fd994.pdf $>$ Acceso 12 de noviembre de 2015. 
Cortés, Fernando y Rubalcava, Rosa (1984) Técnicas estadísticas para el estudio de la desigualdad social. (México, El Colegio de México).

Diario Oficial de El Salvador. (Varios años) en $<$ http://www.imprentanacional.gob.sv/index.php/servicios/en-linea/ciudadano/archivodigital-del-diario-oficial> Acceso 25 marzo de 2016.

Dirección General de Estadísticas y Censos, DIGESTYC (varios años) Encuesta de Hogares de Propósitos Múltiples en <http://www.digestyc.gob.sv/index.php/temas/des/ehpm/publicaciones-ehpm.html> Acceso 15 de enero 2016.

Fairris, Davis; Popli, Gurleen y Zepeda, Eduardo (2005) "Minimum wages and the Wage Structure in Mexico" in Review of Social Economy Vol. LXVI, No 2 Junio 2008 en < http://www.tandfonline.com/doi/pdf/10.1080/00346760701691489> Acceso 18 de octubre de 2015.

Fundación Salvadoreña para el Desarrollo Económico y Social, FUSADES (2010) El impacto de los salarios mínimos en el mercado de Trabajo en El Salvador. (San Salvador, FUSADES) en <http://www.opinandoenelsalvador.com/wpcontent/uploads/2009/06/mercadolaboralsalariominimoelsalvador2010.pdf> Acceso 30 de septiembre de 2015.

Gindling, Thomas y Terrell, Katherine (2007) "The effects of Multiple Minimum Wages Throughout the Labor Market. The case of Costa Rica" En Labour economics, volume $14, \quad$ issue 3 pp. 485-511 en < https://www.researchgate.net/publication/222552444_The_Effects_of_Multiple_Minim um_Wages_throughout_the_Labour_Market_The_Case_of_Costa_Rica > Acceso 20 de noviembre de 2015.

Ibisate, Francisco (1994) “Aportes económicos de las matrices 1978-1990 a los programas de desarrollo: 1994-1999” en Revista Realidad número. 39, junio-julio 1994 en http://www.uca.edu.sv/revistarealidad/archivo/4f16d6a7c0b54aporteseconomicos.pdf $>$ Acceso 24 de febrero 2016.

International Labor Organization, ILO (2015) Global Wage Report 2014/15: Wages and Income Inequality en <http://www.ilo.org/wcmsp5/groups/public/---dgreports/--dcomm/---publ/documents/publication/wcms_324678.pdf> Acceso 25 de noviembre de 2015.

Keynes, John Maynard (2003) Teoría General de la ocupación, el interés y el dinero. (México, Fondo de Cultura Económica, $4^{\circ}$ Edición).

Maurizio, Roxana (2014) Impacto distributivo del salario mínimo en la Argentina, el Brasil, Chile y el Uruguay en http://repositorio.cepal.org/bitstream/handle/11362/37208/LCL3825_es.pdf;jsessionid= 3BF9F16005E9C26EA31C61D1F5EEB511? sequence=1> Acceso 13 de octubre de 2015.

Pérez Aguilar, D. Y Villalobos Dintrans, C. (2014) Efectos e impactos del salario mínimo en América Latina: una revisión sistemática de las investigaciones realizadas. Ponencia presentada en el VIII Encuentro chileno de sociología, Serena 2014 en < 
http://actacientifica.servicioit.cl/biblioteca/gt/GT27/GT27_PerezAguilar_VillalobosDint rans.pdf> Acceso 10 de diciembre de 2015. 


\section{Anexo 1 \\ Salarios promedio y variación de salarios promedio. Algunos apuntes procedimentales}

Cálculo de salario promedio por sector económico

El cálculo del salario promedio del sector secundario y del sector terciario se realizó dividiendo el total de remuneraciones pagadas en ese sector entre el número de personas empleadas en ese sector. Este salario promedio así calculado, es un salario ponderado por el peso que cada rama de actividad tiene en el empleo en el sector en cuestión, tal como se muestra a continuación.

Sea el salario promedio del sector "s" (secundario) en el año " $t$ " igual al cociente del monto de remuneraciones pagadas en el sector y el número de personas empleadas en ese sector. A su vez, el monto de remuneraciones pagadas del sector, es la suma del monto de remuneraciones pagadas en cada rama productiva "i"; así como el total de personas empleadas es la suma de las personas empleadas en cada rama productiva " $i$ ", ambas en el año "t". En parámetros, lo anterior se expresa así:

a)

$$
W m e_{s t}=\frac{\sum_{i=1}^{n} W_{i t}}{\sum_{i=1}^{n} T_{i t}}=\frac{T_{1 t} w_{1 t}+T_{2 t} w_{2 t}+\ldots+T_{n t} w_{n t}}{T_{1 t}+T_{2 t}+\ldots+T_{n t}}=\frac{\sum_{i=1}^{n} T_{i t} w_{i t}}{\sum_{i=1}^{n} T_{i t}}
$$

Introduciendo operaciones algebraicas que no alteran la esencia de la expresión anterior, se puede descubrir una forma diferente, de tal suerte que se evidencie que el cálculo realizado de esta manera, incluye una ponderación por el peso del empleo de cada rama en el sector.

b) $\quad W m e_{s t}=\left(\frac{1}{\sum_{i=1}^{n} T_{i t}}\right) \sum_{i=1}^{n} T_{i t} w_{i t}=\sum_{i=1}^{n} \frac{T_{i t} w_{i t}}{\sum_{i=1}^{n} T_{i t}} \quad$, pero a su vez, $\frac{T_{i t}}{\sum_{i=1}^{n} T_{i t}}=\varphi_{i t}$ esta expresión muestra el peso relativo que tiene el empleo en la rama "i" en el año " $\mathrm{t}$ ", en el total de empleo del sector en el año " $t$ ".

Considerando lo anterior, el cálculo del salario promedio para el sector "s" en el año " $t$ " puede re-expresarse como sigue:

c) $\quad W m e_{s t}=\sum_{i=1}^{n} \varphi_{i t} w_{i t}$, lo cual muestra que la importancia que tiene el salario pagado en cada rama "i" sobre el salario promedio del sector "s" en el año "t", depende de qué tan importante sea el empleo en esa rama en relación con el empleo total en el sector "s".

Variación del salario promedio por sector productivo

Con los salarios promedio calculados de la manera antes descrita, las variaciones intertemporales en su monto, pueden tratarse con el operador diferencia, utilizadas para 
estudios dinámicos en tiempo discreto. El procedimiento anterior permite descomponer la variación, de tal manera que puede identificarse sus elementos constitutivos. En este caso particular, interesa asociar las variaciones en el salario promedio con las variaciones en el ponderador del empleo y con las variaciones en el salario promedio pagado en cada rama productiva del sector.

a) $W m e_{s t}=\sum_{i=1}^{n} \varphi_{i t} w_{i t} \Rightarrow \Delta W m e_{s t}=\sum_{i=1}^{n} \Delta \varphi_{i t} w_{i t} \quad$, las variaciones en el salario promedio del sector resultarían de la sumatoria de las variaciones en el salario promedio de las ramas productivas que lo componen. Pero este a su vez depende de las variaciones en sus componentes: su peso en el empleo del sector y el salario nominal promedio.

b) $\Delta \varphi_{i t} w_{i t}=w_{i t-1} \Delta \varphi_{i t}+\varphi_{i t-1} \Delta w_{i t}+\Delta \varphi_{i t} \Delta w_{i t}$, aplicando la regla de la diferencia de un producto, se obtiene la expresión anterior, que permite identificar tres elementos:

a. $w_{i t-1} \Delta \varphi_{i t}$, muestra la variación debida a las variaciones en el peso relativo del empleo de la rama respecto al sector.

b. $\varphi_{i t-1} \Delta w_{i t}$, muestra la variación debida a las variaciones en el salario nominal promedio de cada rama.

c. $\Delta \varphi_{i t} \Delta w$, muestra un elemento de variación conjunta. Se espera que este valor tienda a cero a medida que las variaciones en los componentes sea más pequeña. En el caso de que las variaciones ocurran exclusivamente debido a cambios en uno solo de los componentes, es decir, que cambie solo el peso en el empleo o solo el monto nominal de salario promedio de la rama (en parámetros así: $\Delta w_{i t}=0 \vee \Delta \varphi_{i t}=0$ ); este componente será cero y se evidenciará la procedencia del cambio en el salario promedio del sector, sea ésta fruto de cambios en el empleo o cambios en las remuneraciones nominales.

Fuente: Elaboración propia. 
Anexo 2

PEA ocupada en la zona urbana, según categoría ocupacional y cobertura ${ }^{\text {a/ }}$ del Instituto Salvadoreño del Seguro Social (ISSS)

Años seleccionados

\begin{tabular}{|c|c|c|c|c|c|c|c|c|c|c|c|c|}
\hline \multirow{2}{*}{$\begin{array}{c}\text { Categorías } \\
\text { ocupacionales }\end{array}$} & \multicolumn{3}{|c|}{2003} & \multicolumn{3}{|c|}{2007} & \multicolumn{3}{|c|}{2011} & \multicolumn{3}{|c|}{2014} \\
\hline & Total & Cubier. & $\%$ & Total & Cubier. & $\%$ & Total & Cubier. & $\%$ & Total & Cubier. & $\%$ \\
\hline TOTAL & 1440.090 & 657.687 & $46 \%$ & 1342.946 & 612.858 & $46 \%$ & 1477.141 & 656.386 & $44 \%$ & 1581.598 & 768.215 & $49 \%$ \\
\hline Patrono & 85.894 & 22.580 & $26 \%$ & 75.031 & 20.181 & $27 \%$ & 65.313 & 19.702 & $30 \%$ & 76.211 & 22.101 & $29 \%$ \\
\hline Cooperativista & 297 & 59 & $20 \%$ & 327 & - & - & - & - & - & - & - & - \\
\hline Asalariado permanente & 741.113 & 570.525 & $77 \%$ & 687.756 & 527.715 & $77 \%$ & 738.632 & 564.219 & $76 \%$ & 842.609 & 647.436 & $77 \%$ \\
\hline Otros & 2.575 & 505 & $20 \%$ & 2.325 & 173 & $7 \%$ & 427 & - & - & 309 & 89 & $29 \%$ \\
\hline Asalariado /cubierto & \multicolumn{3}{|c|}{$91 \%$} & \multicolumn{3}{|c|}{$90 \%$} & \multicolumn{3}{|c|}{$89 \%$} & \multicolumn{3}{|c|}{$88 \%$} \\
\hline
\end{tabular}

a/ La cobertura implica ser cotizante o ser beneficiario/a. En la categoría Asalariado permanente se concentra la mayor parte de cotizantes.

Fuente: Elaboración propia con datos de EHPM 2003, 2007, 2011 y 2014. 


\section{Anexo 3}

\begin{tabular}{|c|c|c|c|c|c|c|c|}
\hline \multicolumn{8}{|c|}{$\begin{array}{c}\text { Actividades económicas del sector secundario y sector terciario, según salario nominal promedio. Orden ascendente. En } \\
\text { dólares mensuales por persona. }\end{array}$} \\
\hline Actividades $^{\mathrm{a} /}$ & Trab. & Wme & Actividades & Trab. & Wme & Crec. Trab. & $\begin{array}{c}\text { Crec. Salario } \\
\text { medio }\end{array}$ \\
\hline $\begin{array}{l}\text { Textiles, prendas de vestir e ind. Del } \\
\text { cuero }\end{array}$ & 97.309 & 227,39 & Restaurantes y hoteles & 25.470 & 321,38 & $85 \%$ & $40 \%$ \\
\hline Restaurantes y hoteles & 13.804 & 229,25 & Servicios personales y a los hogares & 14.837 & 346,55 & $55 \%$ & $18 \%$ \\
\hline Trabajos de agua y suministros & 253 & 287,61 & Trabajos de agua y suministros & 1.321 & 384,67 & $422 \%$ & $34 \%$ \\
\hline $\begin{array}{l}\text { Inmobiliarias y servicios a los } \\
\text { negocios }\end{array}$ & 62.777 & 290,40 & Construcción & 23.518 & 403,79 & $-13 \%$ & $29 \%$ \\
\hline Servicios personales y a los hogares & 9.575 & 293,35 & Inmobiliarias y servicios a los negocios & 117.352 & 414,14 & $87 \%$ & $43 \%$ \\
\hline $\begin{array}{l}\text { Manuf. De madera, art. De madera y } \\
\text { mueblería }\end{array}$ & 1.980 & 300,94 & Comercio al por menor & 97.876 & 426,00 & $23 \%$ & $40 \%$ \\
\hline Transporte y almacenamiento & 13.316 & 312,76 & Servicios comunitarios y sociales & 53.735 & 451,43 & $18 \%$ & $19 \%$ \\
\hline Construcción & 26.994 & 312,80 & Recreación y servicios culturales & 6.875 & 461,36 & $46 \%$ & $37 \%$ \\
\hline Recreación y servicios culturales & 4.695 & 335,64 & Transporte y almacenamiento & 27.277 & 467,00 & $105 \%$ & $49 \%$ \\
\hline Industrias metálicas básicas & 2.512 & 350,49 & Industrias metálicas básicas & 4.433 & 470,33 & $76 \%$ & $34 \%$ \\
\hline $\begin{array}{l}\text { Manufactura de alimentos, bebidas y } \\
\text { tabaco }\end{array}$ & 29.011 & 373,68 & $\begin{array}{l}\text { Manufactura de alimentos, bebidas y } \\
\text { tabaco }\end{array}$ & 35.870 & 490,05 & $24 \%$ & $31 \%$ \\
\hline
\end{tabular}




\begin{tabular}{|c|c|c|c|c|c|c|c|}
\hline Servicios comunitarios y sociales & 45.434 & 378,15 & $\begin{array}{l}\text { Manuf. De productos de minerales no } \\
\text { metálicos exc. Productos de petróleo } \\
\text { y caucho }\end{array}$ & 5.987 & 500,97 & $-1 \%$ & $21 \%$ \\
\hline $\begin{array}{l}\text { Manuf. De químicos y químicos, } \\
\text { petróleo, carbón, caucho y productos } \\
\text { plásticos }\end{array}$ & 14.777 & 385,01 & $\begin{array}{l}\text { Manuf. De químicos y químicos, } \\
\text { petróleo, carbón, caucho y productos } \\
\text { plásticos }\end{array}$ & 18.266 & 513,33 & $24 \%$ & $33 \%$ \\
\hline $\begin{array}{l}\text { Manuf. De productos de minerales no } \\
\text { metálicos exc. Productos de petróleo } \\
\text { y caucho }\end{array}$ & 6.072 & 415,65 & Otras industrias manufactureras & 2.301 & 536,98 & $21 \%$ & $103 \%$ \\
\hline Comercio al por mayor & 7.276 & 425,10 & Comercio al por mayor & 24.091 & 545,34 & $231 \%$ & $28 \%$ \\
\hline $\begin{array}{l}\text { Manuf. De papel, productos de papel, } \\
\text { impresión y publicidad }\end{array}$ & 6.921 & 435,08 & $\begin{array}{l}\text { Manuf. De productos de metal } \\
\text { fabricados, maquinaria y equipo }\end{array}$ & 10.405 & 565,04 & $37 \%$ & $85 \%$ \\
\hline Actividades financieras & 19.845 & 467,58 & $\begin{array}{l}\text { Manuf. De papel, productos de papel, } \\
\text { impresión y publicidad }\end{array}$ & 8.918 & 574,86 & $29 \%$ & $32 \%$ \\
\hline Administración pública y defensa & 866 & 532,34 & Actividades financieras & 24.624 & 621,16 & $24 \%$ & $33 \%$ \\
\hline Seguros de toda clase & 2.532 & 654,86 & Seguros de toda clase & 2.986 & 732,36 & $18 \%$ & $12 \%$ \\
\hline Comunicaciones, radio, correo, telef. & 4.216 & 659,43 & Comunicaciones, radio, correo, telef. & 13.000 & 753,36 & $208 \%$ & $14 \%$ \\
\hline Electricidad, gas y vapor & 2.627 & 845,18 & Electricidad, gas y vapor & 4.118 & 862,60 & $57 \%$ & $2 \%$ \\
\hline Organizaciones internacionales & 515 & 1335,28 & Organizaciones internacionales & 615 & 1729,29 & $19 \%$ & $30 \%$ \\
\hline Total de personas cotizantes & 465.927 & & & 614.374 & & & \\
\hline
\end{tabular}

${ }^{\text {a/ }}$ Desagregadas a 2 dígitos de la CIIU revisión 2.

Fuente: Elaboración propia con datos de ISSS sistematizados por Barrera y Valle (2015) 


\section{ANEXO 4}

Proporción que el salario mínimo representa respecto al salario promedio por ramas productivas. 2003 y 2014 Salarios en dólares nominales por persona al mes

\begin{tabular}{|c|c|c|c|c|c|c|c|c|}
\hline \multicolumn{9}{|c|}{ Sector Secundario } \\
\hline \multirow[t]{2}{*}{ Actividad } & \multicolumn{4}{|c|}{2003} & \multicolumn{4}{|c|}{2014} \\
\hline & Salario medio & Salario Mín. & Smín/Sme & \%trab. & Salario medio & Salario Mín. & Smín/Sme & \%trab \\
\hline Manufactura de alimentos, bebidas y tabaco & 373,68 & 154,5 & 0,41 & $15 \%$ & 490,05 & 237,12 & 0,48 & $18 \%$ \\
\hline Textiles, prendas de vestir e ind. Del cuero & 227,39 & 151,2 & 0,66 & $49 \% 3$ & 363,71 & 202,80 & 0,56 & $40 \%$ \\
\hline Manuf. De madera, art. De madera y mueblería & 300,94 & 154,5 & 0,51 & $1 \%$ & 435,30 & 237,12 & 0,54 & $2 \%$ \\
\hline $\begin{array}{l}\text { Manuf. De papel, productos de papel, impresión y } \\
\text { publicidad }\end{array}$ & 435,08 & 154,5 & 0,36 & $3 \%$ & 574,86 & 237,12 & 0,41 & $4 \%$ \\
\hline $\begin{array}{l}\text { Manuf. De químicos y químicos, petróleo, carbón, } \\
\text { caucho y productos plásticos }\end{array}$ & 385,01 & 154,5 & 0,40 & $7 \%$ & 513,33 & 237,12 & 0,46 & $9 \%$ \\
\hline $\begin{array}{l}\text { Manuf. De productos de minerales no metálicos } \\
\text { exc. Productos de petróleo y caucho }\end{array}$ & 415,65 & 154,5 & 0,37 & $3 \%$ & 500,97 & 237,12 & 0,47 & $3 \%$ \\
\hline Industrias metálicas básicas & 350,49 & 154,5 & 0,44 & $1 \%$ & 470,33 & 237,12 & 0,50 & $2 \%$ \\
\hline $\begin{array}{l}\text { Manuf. De productos de metal fabricados, } \\
\text { maquinaria y equipo }\end{array}$ & 305,49 & 154,5 & 0,51 & $4 \%$ & 565,04 & 237,12 & 0,42 & $5 \%$ \\
\hline Otras industrias manufactureras & 263,97 & 154,5 & 0,59 & $1 \%$ & 536,98 & 237,12 & 0,44 & $1 \%$ \\
\hline Electricidad, gas y vapor & 845,18 & 158,4 & 0,19 & $1 \%$ & 862,60 & 242,42 & 0,28 & $2 \%$ \\
\hline Trabajos de agua y suministros & 287,61 & 158,4 & 0,55 & $0 \%$ & 384,67 & 242,42 & 0,63 & $1 \%$ \\
\hline Construcción & 312,80 & 158,4 & 0,51 & $14 \%$ & 403,79 & 242,42 & 0,60 & $12 \%$ \\
\hline Total personas cotizantes sector secundario & & & & $100 \%$ & & & & $100 \%$ \\
\hline \multicolumn{9}{|c|}{ Sector Terciario } \\
\hline Actividad & \multicolumn{4}{|c|}{2003} & \multicolumn{4}{|c|}{2014} \\
\hline
\end{tabular}




\begin{tabular}{|c|c|c|c|c|c|c|c|c|}
\hline & Salario medio & Salario Mín. & Smín/Sme & \%trab. & Salario medio & Salario Mín. & Smín/Sme & \%trab \\
\hline Comercio al por mayor & 425,10 & 158,40 & 0,37 & $3 \%$ & 545,34 & 242,42 & 0,44 & $6 \%$ \\
\hline Comercio al por menor & 303,25 & 158,40 & 0,52 & $30 \%$ & 426,00 & 242,42 & 0,57 & $24 \%$ \\
\hline Restaurantes y hoteles & 229,25 & 158,40 & 0,69 & $5 \%$ & 321,38 & 242,42 & 0,75 & $6 \%$ \\
\hline Transporte y almacenamiento & 312,76 & 158,40 & 0,51 & $5 \%$ & 467,00 & 242,42 & 0,52 & $7 \%$ \\
\hline Comunicación radio correo telef. & 659,43 & 158,40 & 0,24 & $2 \%$ & 753,36 & 242,42 & 0,32 & $3 \%$ \\
\hline Actividades financieras & 467,58 & 158,40 & 0,34 & $7 \%$ & 621,16 & 242,42 & 0,39 & $6 \%$ \\
\hline Seguros de toda clase & 654,86 & 158,40 & 0,24 & $1 \%$ & 732,36 & 242,42 & 0,33 & $1 \%$ \\
\hline Inmobiliarias y servicios a los negocios & 290,40 & 158,40 & 0,55 & $23 \%$ & 414,14 & 242,42 & 0,59 & $28 \%$ \\
\hline Administración pública y defensa & 532,34 & 158,40 & 0,30 & $0 \%$ & 447,28 & 242,42 & 0,54 & $0 \%$ \\
\hline Servicios de saneamiento y similares & 176,18 & 158,40 & 0,90 & $1 \%$ & 289,19 & 242,42 & 0,84 & $2 \%$ \\
\hline Servicios comunitarios y sociales & 378,15 & 158,40 & 0,42 & $17 \%$ & 451,43 & 242,42 & 0,54 & $13 \%$ \\
\hline Recreación y servicios culturales & 335,64 & 158,40 & 0,47 & $2 \%$ & 461,36 & 242,42 & 0,53 & $2 \%$ \\
\hline Servicios personales y a los hogares & 293,35 & 158,40 & 0,54 & $4 \%$ & 346,55 & 242,42 & 0,70 & $4 \%$ \\
\hline Organizaciones internacionales & 1335,28 & 158,40 & 0,12 & $0 \%$ & 1729,29 & 242,42 & 0,14 & $0 \%$ \\
\hline Total personas cotizantes sector terciario & & & & $100 \%$ & & & & $100 \%$ \\
\hline
\end{tabular}

Fuente: Elaboración propia con datos de ISSS sistematizados por Barrera y Valle (2015) 
Anexo 5

Evolución de salario mínimo real en Comercio y servicios, Industria manufacturera y Maquila textil y de la confección. Indice 2003=100

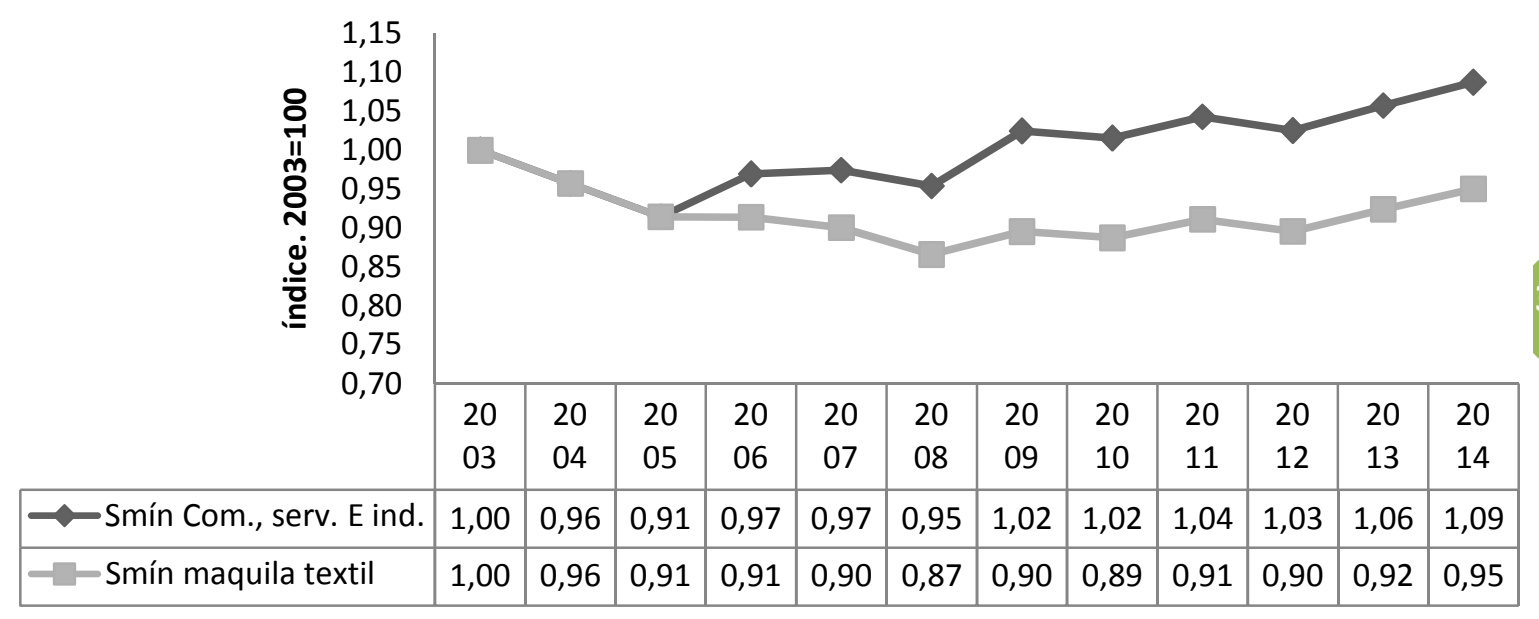

Fuente: Elaboración propia con datos de Diario Oficial, varios años, e IPC según Dirección General de Estadísticas y Censos. 